Canadian

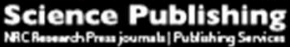

Canadian Journal of Zoology Revue canadienne de zoologie

\title{
Differences in nutrient content of eggs and larvae as indicators for improvement of broodstock nutrition in walleye (Sander vitreus) production
}

\begin{tabular}{|r|l|}
\hline Journal: & Canadian Journal of Zoology \\
\hline Manuscript ID & cjz-2016-0176.R1 \\
\hline Manuscript Type: & Article \\
\hline Complete List of Authors: & $\begin{array}{l}\text { Mejri, Sahar; UQAR, ISMER } \\
\text { Tremblay, Réjean; Université du Québec à Rimouski, ISMER } \\
\text { Vandenberg, Grant; Département des sciences animales, Université Laval, } \\
\text { Quebec, Canada } \\
\text { Moren, Mari; National Institute of Nutrition And Seafood (NIFES), Bergen, } \\
\text { Norway (present working place: Nofima AS, Bergen, Norway } \\
\text { Ben Khemis, Ines; National Institute of Marine Sciences and Technologies, } \\
\text { Tunis, Tunisia } \\
\text { Audet, Céline; Université du Québec à Rimouski, ISMER }\end{array}$ \\
\hline Keyword: & $\begin{array}{l}\text { Walleye, percidae, nutritional needs, fatty acids, amino acids, vitamin A, } \\
\text { embryonic development, egg yolk. }\end{array}$ \\
\hline & \\
\hline
\end{tabular}

\section{SCHOLARONE"}

Manuscripts 
Differences in nutrient content of eggs and larvae as indicators for improvement of broodstock nutrition in walleye (Sander vitreus) production

Sahar Mejri ${ }^{1}$, Réjean Tremblay ${ }^{1}$, Grant Vandenberg ${ }^{2}$, Mari Moren ${ }^{3}$, Ines Ben Khemis ${ }^{4}$ and Céline Audet $^{1}$

${ }^{1}$ Institut des Sciences de la Mer de Rimouski (ISMER), Université du Québec à Rimouski (UQAR), Rimouski, Canada

${ }^{2}$ Département des sciences animales, Université Laval, Québec, Canada

${ }^{3}$ National Institute of Nutrition And Seafood (NIFES), Bergen, Norway (present working place:

Nofima AS, Bergen, Norway)

${ }^{4}$ National Institute of Marine Sciences and Technologies, Tunis, Tunisia

\section{Corresponding author:}

\section{Sahar Mejri}

Phone: +1 418-723-1986 ext 1392, Fax: +1 418-724-1842

Email: Sahar.Mejri@uqar.ca

Address: Institut des Sciences de la Mer (ISMER), UQAR, 310 allée des Ursulines, Rimouski, QC, G5L 2Z9 


\begin{abstract}
The aim of this study was to increase our knowledge about the nutritional needs of walleye (Sander vitreus (Mitchill, 1818)) broodstock. Two dietary treatments were tested: the first consisted of frozen mackerel (Scomber scombrus L., 1758) pieces with a supplement of experimental dry pellets and the second consisted of frozen mackerel pieces with a supplement of commercial trout pellets. Hatching success was highest in eggs from the wild broodstock. Eggs and larvae from wild fish were characterized by the highest levels of linoleic (LOA 18:2 n-6) and linolenic (LNA 18:3 n-3) fatty acids in the neutral lipids. They had the lowest level of docosahexaenoic acid (DHA) in both neutral and polar lipids. The results suggest the importance of the amino acids leucine, lysine, methionine, and serine for better egg survival. Vitamin $A_{1}$ content was similar in eggs from wild fish and the younger broodstock from both treatment groups, but ten times lower in eggs from older broodstock. Vitamin $\mathrm{A}_{2}$ was highest in eggs from wild fish. Our results showed that neither of the two diets really resulted in egg or larval quality that were comparable to that of wild fish.
\end{abstract}

\title{
Keywords:
}

Walleye, Sander vitreus, percidae, nutritional needs, fatty acids, amino acids, vitamin A, embryonic development, egg yolk. 


\section{Introduction}

Fish broodstock diet influences the profiles of fatty acid (FA), amino acid (AA), and vitamin A in embryonic tissues (Torstensen et al. 2000; Cejas et al. 2003). Comparisons between wild and cultured fishes have proven to be a reliable assessment of dietary nutrient requirements (Hixson 2014). In fish eggs, the correct biochemical composition is necessary to meet the developmental needs of embryonic and larval stages (Afzal Khan et al. 2005; Araújo et al. 2012). The nutrients in eggs depend principally on broodstock nutrition (Araújo et al. 2012; Callan et al. 2012). Proteins and lipids are important components of the yolk and act as nutrient sources during biosynthesis.

The role of proteins and the requirement of specific amino acids for the production of good-quality eggs have been better established in marine teleosts (Rønnestad et al. 2003; Moran et al. 2007) than in most freshwater species. Lipids also have an important structural role in addition to their energetic role during egg and larval development. Some fatty acids are considered essential; these include eicosapentaenoic acid (EPA 20:5 n-3), docosahexaenoic acid (DHA 22:6 n-3), and arachidonic acid (ARA 20:4 n-6), all of which are polyunsaturated fatty acids (PUFA) (Sargent et al. 1999), as well as linoleic acid (LOA 18:2 n-6) and linolenic acid (LNA 18:3 n-3) for some freshwater and salmonid fishes (Glencross 2009). However, we know little about how these FA are catabolized by larvae. For instance, it has been shown that starved perch larvae (Perca fluviatilis) use LNA and LOA instead of DHA and ARA (Abi-Ayad et al. 2000).

Among the nutritional components known to affect reproduction and egg and larval development, vitamin A (VA), an essential micronutrient in fish, is of special interest. Indeed, vitamin A, also referred to as retinoids, is vital for reproduction, vision, growth, and immunity 
(Fontagné-Dicharry et al. 2010; La Frano and Burri 2014). Fish store VA as retinyl-esters and use it in the form of retinol $(\mathrm{ROH})$, known as $\mathrm{VA}_{1}$, as well as uncommon forms such as didehydroretinol (dd-ROH) known as vitamin $\mathrm{A}_{2}$ (Morton and Creed 1939; Gross and Budowski 1966). By analyzing retinol, we estimate the level of storage of VA, which is an indicator of the status for the embryos. Vitamin A, whether in deficiency or in excess, has been shown to alter embryonic development as well as cell proliferation and differentiation throughout larval and juvenile growth (reviewed by Ross et al. 2000).

Walleye (Sander vitreus (Mitchill, 1818)) is an important freshwater sport and commercial fish in North America (Hartman 2009). In most hatcheries, walleye broodstock is fed fresh or frozen fish (Summerfelt and Summerfelt 1996; Mejri et al. 2014). In the wild, walleye feed exclusively on living organisms, such as zooplankton, insects, and other fishes. When fish farmers attempt to feed walleye with artificial feed, mortality rates of 50 to $90 \%$ are commonly observed (Summerfelt and Summerfelt 1996).

The aim of this study was to increase our knowledge on the nutritional needs of walleye broodstocks. Two dietary treatments were tested: 1) frozen mackerel (Scomber scombrus), which is rich in DHA (30\% of total fatty acids), supplemented with experimental dry pellets enriched with carotenoids and with mackerel and krill oils to enhance palatability for broodfish, and 2) frozen mackerel supplemented with commercial dry trout pellets. Our hypothesis was that the addition of krill and mackerel oils combined with the high astaxanthin level from the frozen mackerel-experimental dry pellets diet of captive broodstock would increase reproductive performance and egg quality to a level similar or superior to those observed from wild broodstock. 


\section{Materials and Methods}

The experimental protocol received approval from the Institutional Animal Care Committee.

\section{Experimental fish and culture facility}

Walleye broodstock were maintained at the Station Piscicole Trois-Lacs fish farm (Wotton, Quebec, Canada) in $5 \mathrm{~m}^{3}$ circular indoor tanks with a flow-through system (flow rate $1 \mathrm{~L}^{-1} \mathrm{~h}^{-1}$ ) and natural photoperiod. Two groups of fish were reared in separate tanks for a period of 12 months until spawning. At spawning, the experimental pellets fed group, consisted of 28 fiveyear-old (mean weight $[w] 724 \pm 152 \mathrm{~g}$; mean length $[l] 41.3 \pm 3.0 \mathrm{~cm}$ ) and three nine-year-old $(w=1603 \pm 640 \mathrm{~g} ; l=53.3 \pm 6.0 \mathrm{~cm})$ females, and 22 five-year-old $(w=519 \pm 88 \mathrm{~g} ; l=38.0 \pm$ $2.2 \mathrm{~cm})$ and eight nine-year-old $(w=863 \pm 262 \mathrm{~g} ; l=44.9 \pm 4.6 \mathrm{~cm})$ males. The commercial pellets fed group, consisted in 28 five-year-old $(w=712 \pm 178 \mathrm{~g} ; l=41.2 \pm 3.3 \mathrm{~cm})$ and three nine-year-old $(w=2063 \pm 134 \mathrm{~g} ; l=58.4 \pm 2.1 \mathrm{~cm})$ females, and 13 five-year-old $(w=555 \pm 149$ $\mathrm{g} ; l=39.4 \pm 2.9 \mathrm{~cm})$ and four nine-year-old $(w=1282 \pm 154 \mathrm{~g} ; l=50.7 \pm 3.9 \mathrm{~cm})$ males. All fish were fed to satiation, and feeding took place once a day, four times a week from June to endNovember 2012, as fish cease feeding during low winter temperature. Both groups were fed two successive days with experimental dry pellet (EP, $5 \mathrm{~mm}$ diameter) or commercial dry trout pellet (CP, 6 mm; 44/16 from Martin Mills Inc., ON, Canada) followed by one day of fasting and then two days of feeding with frozen mackerel (Scomber scombrus L., 1758) pieces, and this procedure was followed each week from June until the end of November. We thus had an experimental group (EXP) fed with EP + mackerel and a commercial group (COM) fed with CP + mackerel. Therefore, considering ages as well as EXP and COM groups, we had four treatments: experimental - 9 years old (EXP-9Y), experimental - 5 years old (EXP-5Y), 
commercial - 9 years old (COM-9Y), and commercial - 5 years old (COM-5Y). During the feeding period, water temperature was between 18 and $20^{\circ} \mathrm{C}$, and then progressively lowered and maintained at $5{ }^{\circ} \mathrm{C}$ from December 2012 to March 2013. Mean feeding rations were similar in the two groups with values ranging between 2.5 and $2.7 \%$, and 0.7 and $0.9 \%$ of fresh weight/feeding day for mackerel and dry pellet, respectively. Control eggs and larvae were obtained from wild breeders (W), caught in Flood Creek (Lac-du-Cerf, Quebec, Canada); there were nine females ( $w$ $=2556 \pm 686 \mathrm{~g} ; l=56.7 \pm 5.3 \mathrm{~cm})$ and 14 males $(w=2097 \pm 608 \mathrm{~g} ; l=58.1 \pm 6.9 \mathrm{~cm})$.

\section{Pellet composition}

The ingredients of the experimental pellet were fish (herring) meal (35\%; Swimco Canada, Toronto, ON, Canada), mackerel oil (15\%; Swimco Canada), krill oil (2\%; Krill Canada Corporation, Langley, BC, Canada), squid meal (5\%; Zeigler Bros, Inc., Gardners, PA, USA), peas (15\%; Parrheim Foods, Saskatoon, SK, Canada), soy protein HP300 (8\%; Jefo, StHyacinthe, QC, Canada), wheat (10\%; la Seigneurie des Aulnaies Inc., Saint-Roch-des-Aulnaies, QC, Canada), corn gluten (5\%; Meunerie Gérard Soucy Inc., Ste-Croix, QC, Canada), krill meal (3\%, Krill Canada Corporation), vitamins and minerals (0.8\%; Corey Feed Mills Ltd., Fredericton, NB, Canada), lecithin (0.5\%; Vitamin World, Bohemia, NY, USA), astaxanthin (0.04\%; Corey Feed Mills Ltd.), and ethoxiquin (0.015\%; Corey Feed Mills Ltd.). The dry ingredients and $9 \%$ of the mackerel oil were mixed and steam pelleted using a California Pellet Mill. The pellets were then dried in a forced-air oven $\left(30^{\circ} \mathrm{C}, 24 \mathrm{~h}\right)$, sieved, coated with the remaining mackerel and krill oil (6 and $2 \%$, respectively), and stored at $-20{ }^{\circ} \mathrm{C}$ until used. The commercial trout pellets (CP, 44/16 Martin Mills Inc.) were composed of wheat middlings, herring meal, corn gluten meal, soybean meal, poultry meal, feather meal, herring oil, salt, mineral mix, lysine, and choline. 


\section{Spawning and sample collection}

Water temperature was increased from 5 to $9{ }^{\circ} \mathrm{C}$ in April 2013 to stimulate final egg maturation. The oocyte maturation was monitored weekly from 22 April, after females received a first injection of human chorionic gonadotropin (300 IU Kg ${ }^{-1}$ fish), by sampling eggs from 10 to 15 females from each group. Females from the EXP and COM groups (62 and 44\%, respectively) spawned on 1 May 2013. To minimize the effect of different spawning periods on egg quality (Mejri et al. 2014), all eggs used in the experiment were collected on the same day. Fish were anaesthetized with $\mathrm{MS}_{222}\left(5 \mathrm{mg} \cdot \mathrm{L}^{-1}\right)$ in well-oxygenated fresh water and gametes were collected by hand stripping. The standard dry fertilization method (Malison and Held 1996) was used: eggs were collected from each female in a dry $500 \mathrm{~mL}$ plastic bowl and immediately fertilized with the milt of two to three males of the same age. After hardening (2-3 h), fertilized eggs were distributed among $6 \mathrm{~L}$ incubation-jars $(15.8 \mathrm{~cm}$ diameter and $45.7 \mathrm{~cm}$ high), using 3 incubators for each age-group within each diet treatment (12 incubators) and 3 incubators for the wild control treatment for a total of 15 jars. Eggs from six to seven females were pooled for the 5year-old broodstock cohorts and eggs from two to three females were pooled for the 9-year-old broodstock cohorts and wild control treatment. Incubation system was supplied with water (flow rate of 20 L.min ${ }^{-1}$ ) pumped from an external pond; water was drum filtered (90 $\left.\mu \mathrm{m}\right)$, sand filtered (20 $\mu \mathrm{m})$, and finally vacuum degassed before use. Temperature was monitored daily and the upwelling water flow in each incubation jar was regulated to ensure continuous gentle movement of the eggs. From two days after fertilization until just prior to hatching, formaldehyde treatments (50-100 mg formaldehyde per liter of water during $15 \mathrm{~min}$ ) were applied daily to prevent fungal development. 
Twenty-four hours after fertilization, five replicate samplings (30-40 eggs each) were done in each incubator to determine fertilization success. Other samplings were done at 30 degree-days post fertilization (ddpf) (early embryogenesis), $60 \mathrm{ddpf}$ (eggs at an intermediate stage of embryogenesis), $200 \mathrm{ddpf}$ (hatching), and $230 \mathrm{ddpf}$ (prior to first feeding). Three replicates per treatment of approximately $0.2 \mathrm{~g}$ (eggs or larvae) were frozen in liquid nitrogen and stored at $-80^{\circ} \mathrm{C}$ for further biochemical analysis, and two others replicates were preserved in $1 \%$ glutaraldehyde for biometric analysis. Hatching success (\%) was estimated using triplicate sample counts of larvae from a well-mixed incubator for each treatment $(n=3)$, taking into account the initial number of fertilized eggs and the number of dead and viable eggs removed during incubation.

\section{Biometric analysis}

Egg diameter, larval length at hatch, and larval length before first feeding were measured with a high resolution VHX-2000 digital microscope (Keyence, Osaka, Japan) adjusted to 30200x magnification and set in a high dynamic range mode with light shift.

\section{Biochemical analysis}

Lipids were extracted according to the Folch et al. (1957) procedure modified by Parrish (1999) and separated into neutral and polar lipid fractions by silica gel $(30 \times 5 \mathrm{~mm}$ i.d., packed with kieselgel 60, 70-230 mesh; Merck, Darmstadt, Germany) hydrated with 6\% water and eluted with $10 \mathrm{~mL}$ of chloroform:methanol $(98: 2 \mathrm{v} / \mathrm{v})$ for neutral lipids followed by $20 \mathrm{~mL}$ of methanol for polar lipids (Marty et al. 1992). The neutral lipid fraction was further eluted on an activated silica gel with $3 \mathrm{~mL}$ of hexane and diethyl ether to eliminate free sterols. All fatty acid methyl esters (FAME) were prepared as described by Lepage and Roy (1984) and analyzed in MS scan 
mode (ionic range: $60-650 \mathrm{~m} / \mathrm{z}$ ) on a Polaris Q ion trap coupled with a Trace GC (Thermo Finnigan, Mississauga, ON, Canada) (Gendron et al. 2013). All FAME were identified by comparison of retention times with known standards (37 component FAME Mix, PUFA-3, BAME, and menhaden oil; Supelco Bellefonte, PA, USA) and quantified with tricosanoic acid (23:0) and nonadecylic acid (19:0) as internal standards. Chromatograms were analyzed using integration Xcalibur 1.3 software (Thermo Scientific, Mississauga, ON, Canada).

For total amino acid analysis, samples were diluted with $2 \mathrm{~mL}$ distilled water and hydrolyzed with equal parts of $12 \mathrm{~N} \mathrm{HCl}$ containing $10 \%$ phenol at $110{ }^{\circ} \mathrm{C}$ for $24 \mathrm{~h}$. Amino acids were extracted and derivatized using an EZ: faastTM GC-FID analysis kit (Clarke et al. 2010). A volume of $100 \mu \mathrm{L}$ from each sample was mixed with $100 \mu \mathrm{L}$ norvaline $(0.2 \mathrm{mM})$, an internal standard, and n-propanol, and passed through a sorbent tip. The tip was then washed with $200 \mu \mathrm{L}$ Milli-Q water. The sorbent material was injected into an eluting medium consisting of 3:2 sodium hydroxide/n-propanol. Next, $50 \mu \mathrm{L}$ of chloroform and $100 \mu \mathrm{L}$ of iso-octane were added to the solution to form an organic layer containing the amino acids, and derivatization was completed with $1 \mathrm{~N} \mathrm{HCl}$ before being run on a Varian 3800 GC-FID (Agilent Technologies, Palo Alto, CA, USA) to obtain amino acid composition with the exception of taurine and arginine. Each amino acid was quantified with a known quantity of internal standard.

Vitamin A composition was analyzed only on egg samples. The samples were prepared using a saponification method modified from CEN (1999), where samples were boiled for 20 min with $20 \%(\mathrm{w} / \mathrm{w}) \mathrm{KOH}$. High performance liquid chromatography was then used for quantification of total retinol and di-dehydro-retinol (Nöll 1996; Moren et al. 2002). The system consisted of an isocratic pump (Thermo Separation Products, P1000), an auto sampler (Thermo Separation Products, AS3000 auto sampler), a silica column (4 $\mu \mathrm{m}$ spheri, $24 \mathrm{~cm} \times 4.6 \mathrm{~cm}$ I.D., Superspher; Merck), and a diode array detector (Thermo Separation Products, UV6000). The mobile phase 
consisted of $8 \%$ tert-butylmetyl ether in n-heptane; diode array scanning and retention times were used to identify the peaks. Quantification was done using a standard curve for vitamin $\mathrm{A}_{1}$ and a correction factor of 1.64 for vitamin $\mathrm{A}_{2}$. Detection limits for vitamin $\mathrm{A}_{1}$ and vitamin $\mathrm{A}_{2}$ were 18 and 29 ng. ${ }^{-1}$ sample materials, respectively.

\section{Statistical analysis}

Reproductive characteristics of females; fertilization and hatching successes; total lipid; total protein; and vitamin A content were tested with one-way analysis of variance (ANOVA) followed by a posteriori Hsu's multiple comparisons tests after assumptions of homoscedasticity and normality had been verified by Levene and Shapiro-Wilk tests, respectively. These analyses were performed with the JMP 9 package (SAS Institute Inc., Cary, NC). Permutational multivariate analysis of variance (PERMANOVA with 9999 permutations), including a posteriori pair-wise comparisons, was performed on fatty acid and amino acid profiles in mackerel, experimental pellets, and commercial pellets. Fatty acids from neutral and polar fractions and AA profiles in eggs and larvae were tested with PERMANOVA according to two factors: treatment (EXP-9Y, EXP-5Y, COM-9Y, COM-5Y, and W) and degree-days post fertilizations (ddpf) (30 and 60 ddpf for eggs; 200 and 230 ddpf for larvae). Assumptions of homoscedasticity were verified with a PERMDISP test and data were transformed (arcsine square root) when necessary. To analyze the similarity between the profiles, non-metric multi-dimensional scaling (n-MDS) and SIMPER analyses were performed using a Bray-Curtis similarity matrix with PRIMER 6 (v. 6.1.12) and PERMANOVA+ (v. 1.0.2) (Anderson 2001). Linear regression analyses were performed between the hatching and fertilization successes and vitamin A content. 


\section{Results}

\section{Reproductive characteristics}

Results of weight gain of walleye broodstock, condition factor, egg diameter, larval length at hatch and before first feeding, fertilization success, and hatching success are given in Table 1 . Weight gain was significantly higher in younger breeders $\left(F_{[3,102]}=6.6, p<0.0001\right)$. Fulton's $K$ varied between 0.99 and 1.38 with the highest value observed for wild females $\left(F_{[4,68]}=14.12, p\right.$ $<0.0001)$. Egg diameter was larger in eggs from the 9-year-old females with similar results between eggs from the wild and the 5-year-old broodstock $\left(F_{[4,223]}=73.5, p<0.0001\right)$. While hatch success was significantly higher in eggs from the wild fish $\left(F_{\text {hatching }[4,7]}=6.8, p=0.01\right)$, no significant difference was revealed for fertilization success. Lengths at hatch and before first feeding were significantly higher in larvae produced from wild broodstock $\left(F_{\text {at hatch }[4,85]}=40.3\right.$; $\left.F_{\text {before first feeding }[4,85]}=30.6, p<0.0001\right)$.

\section{Nutrient composition of the diet}

Total lipids were significantly higher in mackerel than in experimental and commercial pellets $\left(F_{[2,9]}=18.8, p \leq 0.001\right.$; Table 2$)$. Compared to EP and $\mathrm{CP}$, mackerel contained higher percentages of DHA and EPA. However, EP and CP contained higher amounts of linoleic acid (18:2 n-6). Finally, DHA and EPA percentages were significantly higher in the EP than in the CP $\operatorname{diet}($ Table 2).

Proportions of essential amino acids (EAA) were similar between mackerel, CP, and EP, except for histidine (HIS) and threonine (THR). Threonine was completely absent in both pellets while it made up $7.5 \pm 0.2 \%$ of total AA in mackerel. Mackerel showed the lowest EAA and total protein contents compared to $\mathrm{CP}$ and $\mathrm{EP}\left(\mathrm{EAA}: F_{[2,9]}=43.8\right.$, protein: $F_{[2,9]}=22.2, p \leq 0.001$; 
Table 2). While we did not measure levels of vitamin $A_{1}$ and $A_{2}$ in mackerel, their levels have been reported being 0.12 and $0.05 \mathrm{mg}^{\mathrm{g}} \mathrm{g}^{1}$, respectively (NIFES 2006).

\section{Nutrient composition of eggs and larvae}

Total lipids in eggs did not vary $(p=0.9)$ according to the different factors studied. However, total lipids in larvae varied according to days post fertilization and treatment $\left(F_{\text {ddpf }[1,10]}=7.2\right.$, $\left.F_{\text {treatments }[4,10]}=4.5, p=0.02\right)$. In eggs, total protein and total EAA varied as a function of the interaction between treatments and days post fertilization (protein: $F_{[4,14]}=4.8$; EAA: $F_{[4,14]}=$ $5.0, p=0.01)$, but no variation was observed in larvae $(p \geq 0.06)$.

In both eggs and larvae, the fatty acid composition of the neutral lipids varied according to the different treatments $\left(\right.$ Pseudo- $F_{\text {eggs }[4,14]}=34.4$, Pseudo- $\left.F_{\text {larvae }[4,14]}=39.2, p=0.001\right)($ Table 3). The fatty acid profiles of eggs and larvae obtained from the COM and EXP broodstocks (fed on $[\mathrm{EP}$ or $\mathrm{CP}]+$ mackerel) did not resemble those of the eggs and larvae obtained from the wild broodstock, as shown by n-MDS analysis (Fig. 1). DHA was highest in eggs and larvae from the COM and EXP broodstock groups. However, 20:3 n-3, 18:3 n-3, and 18:2 n-6 were almost three to four times higher in eggs and larvae from the wild fish (Table 3).

In the polar lipid fraction, fatty acids varied according to the different treatments and days post fertilization (eggs: Pseudo- $F_{\text {treatments }[4,13]}=12.1$, Pseudo- $F_{\text {ddpf }[1,13]}=6.1, p \leq 0.006$; larvae: Pseudo- $F_{\text {treatments }[4,14]}=33.9$, Pseudo- $\left.F_{\text {ddpf }[1,14]}=3.8, p \leq 0.04\right)$. The most predominant fatty acids in this fraction were 16:0, 18:1 n-9, EPA, and DHA. In eggs and larvae, 16:0, 18:1 n-9, 20:1 n-9, 20:3 n-3, EPA, and DHA explained most of the variation between the different treatments (Fig. 2), while DHA explained most of the variation in relation to days post fertilization (eggs: $42.5 \pm 6.7 \%$ and $40.2 \pm 4.2 \%$ of total lipid polar FA at 30 and $60 \mathrm{ddpf}$, respectively; larvae: 37.7 
$\pm 6.5 \%$ and $39.7 \pm 6.5 \%$ of total polar lipid FA at 200 and 230 ddpf, respectively). The n-MDS analysis showed a tendency similar to that observed in the neutral lipid fraction, with eggs and larvae produced by the wild broodstock showing distinct FA profiles (Fig. 1).

Leucine (LEU), lysine (LYS), valine (VAL), isoleucine (ILE), and threonine (THR) quantitatively dominated the EAA pool in the eggs and larvae (Tables 4 and 5) of the different treatments. Non-essential amino acids (NEAA), alanine (ALA), serine (SER), aspartic acid (ASP), and glutamic acid (GLU) were the most abundant. The statistical analysis revealed that the interaction between treatments and days post fertilization significantly affected amino acid composition in eggs $\left(\right.$ Pseudo- $F_{[4,14]}=2.4, p=0.01$; Table 4$)$ while only treatments showed a significant effect in larvae (Pseudo- $F_{[4,14]}=9.4, p=0.001$; Table 5). Methionine (MET) and SER percentages were significantly lower in eggs and larvae from wild fish, and SER decreased markedly during embryogenesis in wild eggs, from 6 to $0.1 \%$ of total AA.

Vitamin $A_{1}$ was similar in eggs from wild and 5-year-old broodstock at 30 ddpf. However, it was ten times lower in eggs from the 9-year-old broodstock $\left(F_{[4,7]}=10.3, p=0.005\right.$; Fig. 3). Vitamin $\mathrm{A}_{2}$ was highest in eggs from wild fish $\left(F_{[4,7]}=17.2, p=0.001\right.$; Fig. 3). Positive correlations were found between hatching success and vitamins $\mathrm{A}_{1}$ and $\mathrm{A}_{2}\left(\mathrm{VA}_{1}: F_{[1,10]}=6.8, R^{2}\right.$ $=0.41, p=0.02 ; \mathrm{VA}_{2}: F_{[1,10]}=13.1, R^{2}=0.57, p=0.004$; Fig. 4), but no correlation was found between fertilization success and vitamins $\mathrm{A}_{1}$ and $\mathrm{A}_{2}\left(\mathrm{VA}_{1}\right.$ and $\left.\mathrm{VA}_{2}: R^{2} \leq 0.0005, p \geq 0.94\right)$.

\section{Discussion}

\section{Reproductive characteristics}

Weight gain was significantly higher in 5-year-old fish compared to 9-year-old fish. This might be the result of a genetic predisposition (maximum size achieved for older fish). For 
instance, it has been observed in whitefish (Coregonus lavaretus L., 1758) that younger broodstock ( 1 and 2 years old) consume food throughout the day while older individuals ( 3 and 4 years old) have decidedly shorter feeding periods (Szczepkowski et al. 2010). Condition factor varies between 0.96 and 1.40 in walleye (Falk et al. 1980). The values observed in the present study are within this range. However, wild fish had better condition than domesticated ones, which may explain the best egg quality in wild broodstock. It also indicates that even though captive broodstocks were fed ad libitum, they seem not to be able to reach an optimal nutritional status. Eggs from wild fish had the best hatching success and the highest larval length at hatch and before first feeding. Hatching success from the 5-year-old broodstock was either better than or similar to older broodstock in both the COM and EXP groups. Previous work showed that female gilthead seabream (Sparus aurata L., 1758) at maturity (3 years) were more fertile and their eggs had better hatching success than older females (Jerez et al. 2012). Similarly, the highest hatching success $(96 \%)$ and larval length at hatch and at initiation of active feeding were found in offspring from younger and wild female common carp (Cyprinus carpio L., 1758) (Aliniya et al. 2013). We did not find any significant difference in fertilization percentages between treatments, suggesting that fertilization was not affected by the tested dietary treatments or the age of broodstock. Similar results were reported in the African moony fish (Monodactylus sebae (Cuvier, 1829)), in which increasing DHA level in diets did not show any significant differences in fertilization or survival percentages between floating and sinking eggs, demonstrating that the tested diets had no obvious effect on these descriptors (Ohs et al. 2013).

\title{
Egg and larvae biochemical indicators
}

\author{
a) Lipids and fatty acids
}


Our study showed that total lipids in eggs were independent of the dietary treatment. Similar results were also observed in sweetlips fish (Plectorhinchus cinctus (Lacépède, 1801)) (Li et al. 2005), European sea bass (Dicentrarchus labrax L., 1758) (Navas et al. 1997), and in several other species in which egg total lipids were not affected by broodstock diet (Navas et al. 1997; Cejas et al. 2003; Salze et al. 2005). Nevertheless, many other species with contrasting diets resulted in egg total lipids that were affected by diet, reviewed in Rainuzzo et al. (1997).

Our results showed that high levels of dietary DHA were mainly reflected in the neutral fatty acid profiles of eggs and larvae. For instance, eggs and larvae from the EXP and COM treatments, which were fed mackerel containing 30\% DHA, retained the highest percentages of DHA when compared to wild individuals (Table 3). The lower hatching success in eggs from broodstock fed both dietary treatments (mackerel + CP or EP) might be related to the high levels of highly unsaturated fatty acids (HUFA) in eggs and larvae. Earlier studies have shown that excessive levels of dietary HUFA, i.e., DHA, EPA, and ARA, can negatively affect the quality of eggs and larvae, adversely impact survival rate, and lower fecundity in a large variety fish species such as brill (Scophthalmus rhombus L., 1758) (Hachero-Cruzado et al. 2012), Nile tilapia (Oreochromis niloticus L., 1758) (Santiago and Reyes 1993), Japanese flounder (Paralichthys olivaceus L., 1758) (Furuita et al. 2000), sweetlips (Li et al. 2005), Japanese eel (Anguilla japonica (Temminck and Schlegel, 1846)) (Furuita et al. 2007), and gourami (Trichopodus trichopterus (Pallas, 1770)) (Seifi Berenjestanaki et al. 2014). The eggs and larvae of wild fish in our study had significantly higher levels of 18:2n-6, 18:3n-3, and 20:3n-3. This suggests that the fatty acid profiles in eggs and larvae may be due to the fatty acid content in the diet or be related to a specific requirement in fish related to physiological adaptations to their environment.

The fatty acid requirements of freshwater fish have been classified into three types: the rainbow trout type, the tilapia type, and the carp type (Teshima 1985). Rainbow trout require n-3 
PUFA like 18:3 n-3, tilapia requires n-6 PUFA like 18:2 n-6, and carp require both n-3 and n-6 PUFA. In our study, the high levels of 18:3 n-3 and 18:2 n-6 in wild walleye eggs and larvae suggest that walleye belong to "carp type." The results showed that the levels of 18:2 n-6 and 18:3 n-3 in both types of pellets were higher than in mackerel. However, this was not reflected in the FA profiles of eggs and larvae of domesticated broodstock. It most likely suggests either that broodstock did not eat enough pellets or that the amount assimilated from this fraction of the diet was not large enough to be detected in egg and larva FA profiles.

Our results showed that polar FA profiles differed according to treatment and degree-days post fertilization. These results are in contrast with previous studies that showed rather a conservative characteristic of the polar fraction (Czesny and Dabrowski 1998; Furuita et al. 2002; Araújo et al. 2012). For instance, the polar fraction of walleye and Japanese flounder egg lipids, in particular DHA, EPA, and ARA, was noticeably less affected by the broodstock's nutritional status (Czesny and Dabrowski 1998). In the polar lipid fraction, we observed high percentages of n-9 MUFA in groups fed the tested dietary treatments. However, the source of these FA (mackerel or pellets or both) is unclear. These monoenoic FA are a characteristic feature of farmed fish that are fed diets rich in oils derived from North Atlantic fish (mackerel in this study) (Sargent et al. 1999) or pellets enriched with these FA (the EXP and COM pellets both contained high levels of MUFA). The DHA variations in the polar lipid fraction during embryogenesis (from 30 to $60 \mathrm{ddpf}$ ) and larval development (from 200 to $230 \mathrm{ddpf}$ ) suggest that polar lipids seem to have an energetic role and not to be only involved in the structural function of cell membranes (Wiegand et al. 2004). Moreover, the results most likely suggest that levels of $\approx 25 \%$ DHA and $>5 \%$ of 18:2 n-6 and 18:3 n-3 of total neutral FA could be possible minimal levels for egg and larva performance. 


\section{b) Proteins and amino acids}

Our results suggest the importance of LEU, LYS, VAL, ILE, ALA, ASP, SER, and GLU, since they were the most prevalent amino acids measured in walleye eggs and larvae, with the highest values reported for LYS and LEU in EAA fraction. Our results also suggest possible minimal levels of certain amino acids such as methionine and serine $(>0.1 \%$ and $>6 \%$ of total AAs, respectively). Methionine levels in eggs and larvae of wild fish $(0.1$ and $0.3 \%$ of total AAs, respectively) were 20 times lower than the levels detected in eggs and larvae from the EXP and COM treatments, and yet hatching success was the highest in eggs from wild broodstock. This indicates that higher levels of this essential amino acid may not be necessary for the production of walleye eggs of good quality. Its high percentages in domesticated eggs and larvae are probably due to its high content in the diet. Some studies have shown that an increased dietary MET was not harmful for rainbow trout (Cowey et al. 1992). Methionine has been shown to have growth-promoting effects in some species (Finn and Fyhn 2010). Methionine is one of the most widely used AAs due to its general availability and importance as one of most limiting EAA in plant protein ingredients, such as soy- and corn-based meals (NRC 2011).

Serine was significantly higher in eggs and larvae from fish fed tested diets and decreased drastically during embryogenesis in the wild group, suggesting that it was used as an energy source. An important role for SER has been suggested during walleye ontogeny (Mejri et al. 2014). Indeed, higher SER content was associated with better egg quality (Akiyama et al. 1997).

We found that LEU and LYS proportions were important in eggs and larvae. Other studies showed that a high level of LEU in channel catfish (Ictalurus punctatus (Verreaux, 1866)) eggs was an indicator of good egg quality (Lochmann et al. 2007; Sink et al. 2010). High LEU levels have been identified as an indicator that broodstock diets provide sufficient amounts of amino acids needed to synthesize vitellogenin, the primary precursor of yolk proteins in teleosts (Choo 
et al. 1991; Lochmann et al. 2007; Sink et al. 2010). In our study, LYS percentages in eggs and larvae were around $6 \%$ of total AAs but were not significantly different between treatments. A dietary LYS requirement has been identified for domesticated fish, and it ranges from 1.2 to $6.2 \%$ of the diet (Borlongan and Benitez 1990; Akiyama et al. 1997; Ahmed and Khan 2004). Appropriate dietary LYS levels facilitate the use of other EAA because LYS reduces the oxidation rate of other amino acids (Nunes et al. 2014).

\section{c) Vitamin A}

Our results showed that $\mathrm{VA}_{2}$ levels were 10 times higher than $\mathrm{VA}_{1}$ levels in walleye eggs and larvae; this difference has already been observed in other freshwater species (Palace and Werner 2006; Gesto et al. 2012; La Frano and Burri 2014). Moreover, $\mathrm{VA}_{2}$ was significantly higher in eggs from wild broodstock and these eggs had better quality indicators than those from farmed fish. This suggests that $\mathrm{VA}_{2}$ could have a specific role in walleye egg development, though it is still unclear whether freshwater fish are able to use of $\mathrm{VA}_{2}$ more efficiently during egg development. Similar results were found in Japanese flounder eggs, where $\mathrm{VA}_{2}$ content was significantly higher in wild eggs (Wang et al. 2010). In a study conducted by La Frano and Burri (2014), the diet of North American farm-raised freshwater fish was supplemented with a combined high and low concentrations of $\mathrm{VA}_{1}$ and $\mathrm{VA}_{2}$, respectively. The results showed that $\mathrm{VA}_{2}$ concentrations were higher than $\mathrm{VA}_{1}$ in fish liver, suggesting that $\mathrm{VA}_{2}$ is preferentially accumulated. Previous studies showed similar results, demonstrating that $\mathrm{VA}_{2}$ accumulates preferentially in the liver of most freshwater fish (Doyon et al. 1998; Roos et al. 2002; Gesto et al. 2012)

We found no clear relationship between fertilization percentages and VA $\left(\mathrm{VA}_{1}\right.$ and $\left.\mathrm{VA}_{2}\right)$, indicating that fertilization percentage seems independent of the VA concentration in the eggs. 
However, a positive correlation was found between hatching success and VA $\left(\mathrm{VA}_{1}\right.$ and $\left.\mathrm{VA}_{2}\right)$. A positive correlation was revealed between egg hatching and survival percentages and vitamins $\mathrm{A}$ and $E$ in Japanese eel eggs (Furuita et al. 2009). Indeed, in this study, VA in eggs with high hatching success $(80 \%)$ was higher than levels in eggs with low hatching success. A similar relationship has also been shown in some crustaceans. For instance, fecundity and hatching percentages in Chinese white shrimp (Penaeus chinensis (Osbeck, 1765)) were positively correlated with egg VA content (Mengqing et al. 2004). Levels of carotenoids, which serve as vitamin A precursors, and hatching success were measured in farmed rainbow trout (Onchorhynchus mykiss (Walbaum, 1792)); the results indicated that eggs with lower carotenoids content had lower hatching percentages and that this level was critical to egg performance e.g. Palace and Werner (2006). Wang et al. (2010) showed that the lower VA content in eggs from farmed fish compared to wild ones may lower larval quality in Japanese flounder; the authors suggested that this could be resolved by supplementation of adequate proportions of VA in broodstock diet. Vitamin A plays an important role as a physiological regulator of cell growth and differentiation. The hatching success and survival of 3-day-old larvae of bighead carp (Aristichthys nobilis (Richardson, 1845)) improved with VA supplementation while a deficiency in the broodstock diet slightly decreased relative fecundity (Santiago and Gonzal 2000). Considering all the above evidence, the dietary content should be sufficient to guaranty in walleye eggs minimal amounts of $\geq 0.2$ and $2.0 \mathrm{mg} \cdot \mathrm{g}^{-1}$ for $\mathrm{VA}_{1}$ and $\mathrm{VA}_{2}$, respectively.

Eggs from wild broodstock showed the best hatching success. The use of experimental pellets enriched with krill and mackerel oils and astaxanthin did not show any increase in egg performance. Eggs and larvae from the EXP and COM treatments retained the highest percentage of DHA (up to 31\%). However, wild eggs and larvae had highest levels of linoleic (18:2 n-6) and linolenic (18:3 n-3) fatty acids. The results suggest the importance of the amino acids LYS, LEU, 
MET, and SER for egg and larva performance. Vitamin $\mathrm{A}\left(\mathrm{VA}_{1}\right.$ and $\left.\mathrm{VA}_{2}\right)$ contents were positively correlated with hatching success and were highest in wild eggs.

To improve walleye production, more work has to be done to develop a good broodstock diet since the use of mackerel, as food is far from optimal. Dry pellets are a better alternative for broodstock nutrition, but further work has to be done to determine the specific requirements for each nutrient. We determined some of the minimal nutrient requirements for eggs, which probably need at least 5\% 18:2 n-6 and 18:3 n-3 and $\approx 25 \%$ DHA in the total neutral FA fraction to promote higher hatching success. Moreover, the results demonstrated the importance of methionine and serine during embryogenesis, suggesting minimal levels of 0.1 and $6 \%$, respectively, of total amino acids. Vitamin $\mathrm{A}\left(\mathrm{VA}_{1}\right.$ and $\left.\mathrm{VA}_{2}\right)$ was positively correlated with hatching success, revealing its important role in the early life stages of walleye and the necessity of its adequate incorporation into the diet of broodstock. Dietary contents should be sufficient to guaranty in the eggs amounts $\geq 0.2$ and $2.0 \mathrm{mg} \cdot \mathrm{g}^{-1}$ for $\mathrm{VA}_{1}$ and $\mathrm{VA}_{2}$, respectively.

\section{Acknowledgements}

This study was financially supported by the Société de Recherche et de Développement en Aquaculture Continentale Inc. (SORDAC), the Station Piscicole Trois-Lacs industry partner (Wotton, Quebec, Canada), the Natural Sciences and Engineering Research Council of Canada (NSERC), and the Fonds de recherche du Québec-Nature et Technologies (FRQNT). We are grateful to M. Blanchet and K. Grenier for their extensive help during fieldwork and thank AnneKarin Syversen for her assistance in the vitamin analysis. 


\section{References}

Abi-Ayad, S.M.E.A., Kestemont, P., and Mélard, C. 2000. Dynamics of total lipids and fatty acids during embryogenesis and larval development of Eurasian perch (Perca fluviatilis). Fish Physiol. Biochem. 23: 233-243.

Afzal Khan, M., Jafri, A.K., and Chadha, N.K. 2005. Effects of varying dietary protein levels on growth, reproductive performance, body and egg composition of rohu, Labeo rohita. Aquacut. Nutr. 11: 11-17.

Ahmed, I., and Khan, M.A. 2004. Dietary lysine requirement of fingerling Indian major carp, Cirrhinus mrigala. Aquaculture, 235: 499-511.

Akiyama, T., Oohara, I., and Yamamoto, T. 1997. Comparison of essential amino acid requirements with A/E Ratio among fish species (review paper). Fish. Sci. 63: 963-970.

Aliniya, M., Khara, H., Noveiri, S.B., and Dadras, H. 2013. Influence of age of common carp (Cyprinus carpio) broodstock on reproductive traits and fertilization. Turkish J. Fish. Aquat. Sci. 13: 19-25.

Anderson, M.J. 2001. A new method for non-parametric multivariate analysis of variance. Austral. Ecol. 26: 32-46.

Araújo, B., Honji, R., De Mello, P., and Moreira, R. 2012. The influence of captive breeding on the fatty acid profiles of Salminus hilarii (Characiformes: Characidae) eggs and larvae. Aquacult. Int. 20: 1161-1181.

Borlongan, I.G., and Benitez, L.V. 1990. Quantitative lysine requirement of milkfish (Chanos chanos) juveniles. Aquaculture, 87: 341-347. 
Callan, C.K., Laidley, C.W., Forster, I.P., Liu, K.M., Kling, L.J., and Place, A.R. 2012. Examination of broodstock diet effects on egg production and egg quality in flame angelfish (Centropyge loriculus). Aquacult. Res. 43: 696-705.

Cejas, J.R., Almansa, E., Villamandos, J.E., Badía, P., Bolaños, A., and Lorenzo, A. 2003. Lipid and fatty acid composition of ovaries from wild fish and ovaries and eggs from captive fish of white sea bream (Diplodus sargus). Aquaculture, 216: 299-313.

CEN, 1999. Foodstuffs - determination of vitamin A by high performance liquid chromatography: part 1. Measurement of all-trans retinol and 13-cis retinol. Comité Europèen de Normalisation prEN 12823-1 pp. 1-13, Brussels, Belgium.

Choo, P.S., Smith, T.K., Cho, C.Y., and Ferguson, H.W. 1991. Dietary excesses of leucine influence growth and body composition of rainbow trout. J. Nutr. 121: 1932-1939.

Clarke, M., Parrish, C.C., and Penney, R.W. 2010. Free amino acids as an indicator of egg viability in Atlantic Cod (Gadus morhua). Bull.Aquacult.Assoc.Can. 108 (2): 6-9.

Cowey, C.B., Cho, C.Y., Sivak, J.G., Weerheim, J.A., and Stuart, D.D. 1992. Methionine intake in rainbow trout (Oncorhynchus mykiss), relationship to cataract formation and the metabolism of methionine. J. Nutr. 122: 1154-1163.

Czesny, S., and Dabrowski, K. 1998. The effect of egg fatty acid concentrations on embryo viability in wild and domesticated walleye (Stizostedion vitreum). Aquat. Living Resour. 11: $371-378$.

Doyon, C., Boileau, S., Fortin, R., and Spear, P.A. 1998. Rapid HPLC analysis of retinoids and dehydroretinoids stored in fish liver: comparison of two lake sturgeon populations. J. Fish Biol. 53: 973-986. 
Falk, M.R., Gillman, D.V., and Read, C.J. 1980. Data on the walleye (Stizostedion vitreum) and other species from Mosquito Creek, Northwest Territories, 1973-78. Can. Data Rep. Fish. Aquat. Sci. No. 186, Winnipeg, Manitoba.

Finn, R.N., and Fyhn, H.J. 2010. Requirement for amino acids in ontogeny of fish. Aquacult. Res. 41: 684-716.

Folch, J., Lees, M., and Sloane Stanley, G.H. 1957. A simple method for the isolation and purification of total lipids from animal tissues. Biol. Chem. 226: 497-509.

Fontagné-Dicharry, S., Lataillade, E., Surget, A., Brèque, J., Zambonino-Infante, J.-L., and Kaushik, S.J. 2010. Effects of dietary vitamin A on broodstock performance, egg quality, early growth and retinoid nuclear receptor expression in rainbow trout (Oncorhynchus mykiss). Aquaculture, 303: 40-49.

Furuita, H., Tanaka, H., Yamamoto, T., Shiraishi, M., and Takeuchi, T. 2000. Effects of n-3 HUFA levels in broodstock diet on the reproductive performance and egg and larval quality of the Japanese flounder, Paralichthys olivaceus. Aquaculture, 187: 387-398.

Furuita, H., Tanaka, H., Yamamoto, T., Suzuki, N., and Takeuchi, T. 2002. Effects of high levels of n-3 HUFA in broodstock diet on egg quality and egg fatty acid composition of Japanese flounder, Paralichthys olivaceus. Aquaculture, 210: 323-333.

Furuita, H., Hori, K., Suzuki, S., Sugita, T., and Yamamoto, T. 2007. Effect of n-3 and n-6 fatty acids in broodstock diet on reproduction and fatty acid composition of broodstock and eggs in the Japanese eel Anguilla japonica. Aquaculture, 267: 55-61.

Furuita, H., Unuma, T., Nomura, K., Tanaka, H., Sugita, T., and Yamamoto, T. 2009. Vitamin contents of eggs that produce larvae showing a high survival rate in the Japanese eel Anguilla japonica. Aquacult. Res. 40: 1270-1278. 
Gendron, L., Tremblay, R., Belvin, S., Génard, B., Motnikar, S., and Côté, J. 2013. Condition, survival and growth in situ of hatchery-reared stage IV lobster (Homarus americanus) fed Artemia and lipid-rich wild zooplankton. Aquaculture, 416: 380-389.

Gesto, M., Castro, L.F.C., Reis-Henriques, M.A., and Santos, M.M. 2012. Tissue-specific distribution patterns of retinoids and didehydroretinoids in rainbow trout, Oncorhynchus mykiss. Comp. Biochem. Physiol. B: 161: 69-78.

Glencross, B.D. 2009. Exploring the nutritional demand for essential fatty acids by aquaculture species. Rev. Aquaculture. 1: 71-124.

Gross, J., and Budowski, P. 1966. Conversion of carotenoids into vitamins A(1) and A(2) in two species of freshwater fish. Biochem. J. 101: 747-754.

Hachero-Cruzado, I., Olmo, P., Sánchez, B., Herrera, M., and Domingues, P. 2012. Effects of two diets on lipid composition and reproductive performance of brill (Scophthalmus rhombus) eggs. Aquacult. Res. 43: 1439-1450.

Hartman, G.F. 2009. A biological synopsis of walleye (Sander vitreus). Can. Manuscr. Rep. Fish. Aquat. Sci. No. 2888: 48.

Hixson, S.M. 2014. Fish nutrition and current issues in aquaculture: the balance in providing safe and nutritious seafood, in an environmentally sustainable manner. J. Aquacult. Res Dev. 5: 234 .

Jerez, S., Rodríguez, C., Cejas, J.R., Martín, M.V., Bolaños, A., and Lorenzo, A. 2012. Influence of age of female gilthead seabream (Sparus aurata L.) broodstock on spawning quality throughout the reproductive season. Aquaculture, 350-353: 54-62.

La Frano, M.R., and Burri, B.J. 2014. Analysis of retinol, 3-hydroxyretinol and 3,4didehydroretinol in North American farm-raised freshwater fish liver, muscle and feed. Aquacult. Nutr. 20: 722-730. 
Lepage, G., and Roy, C. 1984. Improved recovery of fatty acid through direct transesterification without prior extraction or purification. J. Lipid Res. 25: 1391-1396.

Li, Y.Y., Chen, W.Z., Sun, Z.W., Chen, J.H., and Wu, K.G. 2005. Effects of n-3 HUFA content in broodstock diet on spawning performance and fatty acid composition of eggs and larvae in Plectorhynchus cinctus. Aquaculture, 245: 263-272.

Lochmann, S.E., Goodwin, K.J., Lochmann, R.T., Stone, N.M., and Clemment, T. 2007. Volume and lipid, fatty acid, and amino acid composition of golden shiner eggs during a spawning season. N. Am. J. Aquacult. 69: 116-126.

Malison, J.A., and Held, J.A., 1996. Reproductive biology and spawning. In Walleye culture manual. NCRAC culture series101. Edited by R.C. Summerfelt. Iowa, Ames, pp. 11-18.

Marty, Y., Delaunay, F., Moal, J., and Samain, J.F. 1992. Changes in the fatty acid composition of Pecten maximus (L.) during larval development. J. Exp. Mar. Biol. Ecol. 163: 221-234.

Mejri, S., Audet, C., Vandenberg, G.W., Parrish, C.C., and Tremblay, R. 2014. Biochemical egg quality in a captive walleye (Sander vitreus) broodstock population relative to ovulation timing following hormonal treatment. Aquaculture, 431: 99-106.

Mengqing, L., Wenjuan, J., Qing, C., and Jialin, W. 2004. The effect of vitamin A supplementation in broodstock feed on reproductive performance and larval quality in Penaeus chinensis. Aquacult. Nutr. 10: 295-300.

Moran, D., Gara, B., and Wells, R.M.G. 2007. Energetics and metabolism of yellowtail kingfish (Seriola lalandi) during embryogenesis. Aquaculture, 265: 359-369.

Moren, M., Næss, T., and Hamre, K. 2002. Conversion of $\beta$-carotene, canthaxanthin and astaxanthin to vitamin A in Atlantic halibut (Hippoglossus hippoglossus) juveniles. Fish Physiol. Biochem. 27: 71-80. 
Morton, R.A., and Creed, R.H. 1939. The conversion of carotene to vitamin A(2) by some freshwater fishes. Biochem. J. 33: 318-324.

Navas, J.M., Bruce, M., Thrush, M., Farndale, B.M., Bromage, N., Zanuy, S., Carrillo, M., Bell, J.G., and Ramos, J. 1997. The impact of seasonal alteration in the lipid composition of broodstock diets on egg quality in the European sea bass. J. Fish Biol. 51: 760-773.

NIFES, 2006. Nutrients, seafood data, Bergen, Norway

Nöll, G.N. 1996. High-performance liquid chromatographic analysis of retinal and retinol isomers. J. Chromatogr. A. 721: 247-259.

NRC, 2011. Nutrient Requirements of Fish and Shrimp. The National Academies Press, Washington DC.

Nunes, A.J.P., Sá, M.V.C., Browdy, C.L., and Vazquez-Anon, M. 2014. Practical supplementation of shrimp and fish feeds with crystalline amino acids. Aquaculture, 431: 20-27.

Ohs, C.L., DiMaggio, M.A., Grabe, S.W., Broach, J.S., Watson, C.A., Breen, N.E., and Barrows, F.T. 2013. Effects of increasing docosahexaenoic acid (DHA) and arachidonic acid (ARA) in brood diets of Monodactylus sebae on fecundity, egg and larval quality, and egg fatty acid composition. N. Am. J. Aquacult. 75: 285-294.

Palace, V.P., and Werner, J. 2006. Vitamins A and E in the maternal diet influence egg quality and early life stage development in fish: a review. Sci. Mar. 70: 41-57.

Parrish, C.C. 1999. Determination of total lipid, lipid classes, and fatty acids in aquatic samples. In Lipids in Freshwater Ecosystems. Edited by M.T. Arts and B.C. Wainman. Springer Verlag, New York, pp. 4-20.

Rainuzzo, J.R., Reitan, K.I., and Olsen, Y. 1997. The significance of lipids at early stages of marine fish: a review. Aquaculture, 155: 103-115. 
Rønnestad, I., Tonheim, S.K., Fyhn, H.J., Rojas, G., Kamisaka, Y., Koven, W., Finn, R.N., Terjesen, B.F., Barr, Y., and Conceição, L.E.C. 2003. The supply of amino acids during early feeding stages of marine fish larvae: a review of recent findings. Aquaculture, 227: 147-164.

Roos, N., Leth, T., Jakobsen, J., Thilsted, S.H. 2002. High vitamin A content in some small indigenous fish species in Bangladesh: perspectives for food-based strategies to reduce vitamin A deficiency. Int. J. Food Sci. Nutr. 53: 425-437.

Ross, S.A., McCaffery, P.J., Drager, U.C., and De Luca, L.M. 2000. Retinoids in embryonal development. Physiol. Rev. 80: 1021-1054.

Salze, G., Tocher, D.R., Roy, W.J., and Robertson, D.A. 2005. Egg quality determinants in cod (Gadus morhua): egg performance and lipids in eggs from farmed and wild broodstock. Aquacult. Res. 36: 1488-1499.

Santiago, C.B., and Reyes, O.S. 1993. Effects of dietary lipid source on reproductive performance and tissue lipid levels of Nile tilapia (Oreochromis niloticus) broodstock. J. Appl. Ichthyol. 9: 33-40.

Santiago, C.B., and Gonzal, A.C. 2000. Effect of prepared diet and vitamins A, E and C supplementation on the reproductive performance of cage-reared bighead carp (Aristichthys nobilis). J. Appl. Ichthyol. 16: 8-13.

Sargent, J., McEvoy, L., Estevez, A., Bell, G., Bell, M., Henderson, J., and Tocher, D. 1999. Lipid nutrition of marine fish during early development: current status and future directions. Aquaculture, 179: 217-229.

Seifi Berenjestanaki, S., Esmaeili Fereidouni, A., Ouraji, H., and Jani Khalili, K. 2014. Influence of dietary lipid sources on growth, reproductive performance and fatty acid compositions 
of muscle and egg in three-spot gourami (Trichopodus trichopterus). Aquacult. Nutr. 20: 494-504.

Sink, T.D., Lochmann, R.T., Pohlenz, C., Buentello, A., and Gatlin, D. 2010. Effects of dietary protein source and protein-lipid source interaction on channel catfish (Ictalurus punctatus) egg biochemical composition, egg production and quality, and fry hatching percentage and performance. Aquaculture, 298: 251-259.

Summerfelt, S.T., and Summerfelt, R.C. 1996. Aquaculture of walleye as a food fish. In Walleye culture manual. Edited by R.C. Summerfelt. North Central Regional Aquaculture Center Publications Office, Iowa State University, Ames, pp. 215-230.

Szczepkowski, M., Szczepkowska, B., Krzywosz, T., Wunderlich, K., and Stabiński, R. 2010. Growth rate and reproduction of a brood stock of European whitefish (Coregonus lavaretus) from Lake Gaładuś under controlled rearing conditions. Arch. Pol. Fish. 18: 311.

Teshima, S., 1985. Lipids. In Fish nutrition and diets. Edited by Y.E. Yone. Koseisha Koseikaku, Tokyo, pp. 20-30.

Torstensen, B., Lie, Ø., and Frøyland, L. 2000. Lipid metabolism and tissue composition in Atlantic salmon (Salmo salar)-Effects of capelin oil, palm oil, and oleic acid-enriched sunflower oil as dietary lipid sources. Lipids, 35: 653-664.

Wang, J.Y., Li, B.S., Ma, J.J., Liu, X.D., Song, Z.D., Miao, S.Y., Li, P.Y., Wang, S.X., Huang, B.S., and Zhang, L.M. 2010. A comparison study of vitamin A, C and E in wild and farmed Japanese flounder Paralichthys olivaceus. J. Fish. Sci. China, 17: 1250-1256.

Wiegand, M.D., Johnston, T.A., Martin, J., and Leggett, W.C. 2004. Variation in neutral and polar lipid compositions of ova in ten reproductively isolated populations of walleye (Sander vitreus). Can. J. Fish. Aquat. Sci. 61: 110-121. 


\section{Tables}

Table 1. Weight gain, condition factor, characteristics of eggs and larvae, and reproductive performance (mean $\pm \mathrm{SD}$ ) of 5- and 9-year-old fish from domesticated broodstocks fed two diet treatments compared to a wild broodstock. Means in a row with different letters are significantly different (ANOVA: $p<0.05$ ). Treatments were defined as follows: Experimental -9 years old (EXP-9Y), experimental -5 years old (EXP-5Y), commercial - 9 years old (COM-9Y), commercial - 5 years old (COM-5Y), and wild (W).

\begin{tabular}{|c|c|c|c|c|c|}
\hline \multicolumn{6}{|l|}{ Diet } \\
\hline \multirow[b]{2}{*}{ Age } & \multicolumn{2}{|c|}{$\begin{array}{l}\text { EXP diet (Mackerel + } \\
\text { experimental pellet) }\end{array}$} & \multicolumn{2}{|c|}{$\begin{array}{l}\text { COM diet (Mackerel + } \\
\text { commercial pellet) }\end{array}$} & \multirow[t]{2}{*}{ Wild } \\
\hline & 5 years & 9 years & 5 years & 9 years & \\
\hline Treatments & EXP-5Y & EXP-9Y & COM-5Y & COM-9Y & $\mathbf{W}$ \\
\hline $\begin{array}{l}\text { Weight gain (g) for } \\
\text { both sexes }\end{array}$ & $213.6 \pm 79.0^{\mathrm{a}}$ & $92.7 \pm 70.3^{b}$ & $235.0 \pm 110.7^{\mathrm{a}}$ & $118.3 \pm 158.2^{\mathrm{b}}$ & - \\
\hline $\begin{array}{l}\text { Condition factor } \\
\mathrm{K}=\left(\text { Mass } / \text { Length }^{3}\right) \times 100\end{array}$ & $1.00^{\mathrm{b}}$ & $1.01^{\mathrm{b}}$ & $0.99^{b}$ & $1.04^{b}$ & $1.38^{\mathrm{a}}$ \\
\hline Egg diameter (mm) & $2.0 \pm 0.1^{b}$ & $2.2 \pm 0.0^{\mathrm{a}}$ & $2.0 \pm 0.0^{b}$ & $2.2 \pm 0.0^{\mathrm{a}}$ & $2.0 \pm 0.0^{\mathrm{b}}$ \\
\hline Larvae at hatch (mm) & $6.8 \pm 0.3^{b}$ & $6.8 \pm 0.2^{b}$ & $6.2 \pm 0.2^{\mathrm{c}}$ & $6.9 \pm 0.3^{b}$ & $7.3 \pm 0.3^{\mathrm{a}}$ \\
\hline $\begin{array}{l}\text { Larvae before first } \\
\text { feeding }(\mathrm{mm})\end{array}$ & $7.1 \pm 0.4^{\mathrm{d}}$ & $7.9 \pm 0.3^{b}$ & $7.5 \pm 0.2^{\mathrm{c}}$ & $7.9 \pm 0.4^{b}$ & $8.4 \pm 0.4^{\mathrm{a}}$ \\
\hline Fertilization $(\%)$ & $90.6 \pm 9.7$ & $97.7 \pm 3.9$ & $82.2 \pm 17.9$ & $89.2 \pm 4.7$ & $87.9 \pm 10.3$ \\
\hline Hatching $(\%)$ & $18.8 \pm 14.5^{\mathrm{b}}$ & $6.9 \pm 2.8^{\mathrm{bc}}$ & $14.9 \pm 11.5^{\mathrm{bc}}$ & $2.4 \pm 1.9^{c}$ & $52.1 \pm 18.3^{\mathrm{a}}$ \\
\hline
\end{tabular}




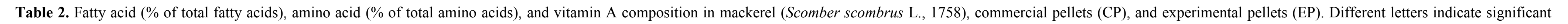
differences among feed types (ANOVA: $p<0.05$ ). We have no data for $\mathrm{VA}_{1}$ and $\mathrm{VA}_{2}$ in $\mathrm{CP}$ and $\mathrm{EP}$

\begin{tabular}{|c|c|c|c|c|c|c|c|}
\hline \multirow[t]{2}{*}{ Fatty acids } & \multicolumn{3}{|c|}{ Diets } & Amino acids & \multicolumn{3}{|c|}{ Diets } \\
\hline & Mackerel & $\mathrm{CP}$ & EP & \multicolumn{4}{|c|}{$\begin{array}{l}\text { Mackerel } \\
\text { Essential amin }\end{array}$} \\
\hline C14:0 & $3.4 \pm 1.3$ & $3.2 \pm 0.1$ & $5.8 \pm 0.0$ & Valine, VAL & $4.8 \pm 0.5$ & $4.8 \pm 0.2$ & $5.3 \pm 0.5$ \\
\hline C16:0 & $15.1 \pm 0.7$ & $12.2 \pm 0.4$ & $14.4 \pm 0.2$ & Leucine, LEU & $6.7 \pm 0.2$ & $8.0 \pm 0.4$ & $8.2 \pm 0.9$ \\
\hline C18:0 & $4.1 \pm 0.8$ & $2.3 \pm 0.1$ & $3.4 \pm 0.0$ & Isoleucine, ILE & $4.0 \pm 0.8$ & $3.4 \pm 0.2$ & $4.5 \pm 0.9$ \\
\hline$\sum \mathrm{SFA} \uparrow$ & $24.2 \pm 4.2$ & $18.8 \pm 3.4$ & $25.4 \pm 4.2$ & Threonine, THR & $7.4 \pm 0.1^{\mathrm{a}}$ & $0.0 \pm 0.0^{\mathrm{b}}$ & $0.0 \pm 0.0^{\mathrm{b}}$ \\
\hline $\mathrm{C} 16: 1$ & $4.5 \pm 0.8$ & $4.8 \pm 0.0$ & $3.6 \pm 0.0$ & Histidine, HIS & $2.7 \pm 0.0^{\mathrm{a}}$ & $1.2 \pm 0.3^{\mathrm{b}}$ & $0.8 \pm 0.1^{\mathrm{b}}$ \\
\hline C18:1 n-9 & $3.1 \pm 0.2^{\mathrm{b}}$ & $19.8 \pm 0.4^{\mathrm{a}}$ & $20.9 \pm 0.7^{\mathrm{a}}$ & Methionine, MET & $2.1 \pm 0.0$ & $1.1 \pm 0.0$ & $1.7 \pm 0.2$ \\
\hline $\mathrm{C} 20: 1 \mathrm{n}-9$ & $8.0 \pm 2.6^{\mathrm{b}}$ & $9.0 \pm 1.0^{\mathrm{b}}$ & $12.6 \pm 0.0^{\mathrm{a}}$ & Phenylalanine, PHE & $2.0 \pm 0.2$ & $2.8 \pm 0.0$ & $2.7 \pm 0.1$ \\
\hline $\mathrm{C} 22: 1 \mathrm{n}-9$ & $14.3 \pm 5.1^{\mathrm{ab}}$ & $18.8 \pm 1.3^{\mathrm{a}}$ & $10.0 \pm 0.3^{\mathrm{b}}$ & Lysine, LYS & $6.2 \pm 0.3$ & $7.3 \pm 1.5$ & $5.9 \pm 0.2$ \\
\hline$\sum$ MUFA & $31.6 \pm 5.0$ & $53.3 \pm 8.4$ & $48.9 \pm 7.6$ & \multicolumn{4}{|c|}{ Non-essential amino acids ${ }^{+}$} \\
\hline $\mathrm{C} 18: 2 \mathrm{n}-6$ & $1.6 \pm 0.3^{\mathrm{c}}$ & $17.3 \pm 0.0^{\mathrm{a}}$ & $4.7 \pm 0.1^{\mathrm{b}}$ & Alanine, ALA & $8.4 \pm 0.1$ & $8.6 \pm 0.2$ & $8.8 \pm 0.7$ \\
\hline C18:3 n-3 & $0.8 \pm 0.1^{\mathrm{b}}$ & $2.1 \pm 0.1^{\mathrm{a}}$ & $0.9 \pm 0.0^{\mathrm{b}}$ & Glycine, GLY & $7.3 \pm 1.0$ & $8.8 \pm 0.6$ & $9.1 \pm 0.9$ \\
\hline $\mathrm{C} 20: 5 \mathrm{n}-3$ & $9.1 \pm 0.4^{\mathrm{a}}$ & $3.2 \pm 0.0^{\mathrm{c}}$ & $6.2 \pm 0.2^{\mathrm{b}}$ & Serine, SER & $24.3 \pm 0.4^{\mathrm{a}}$ & $18.3 \pm 0.6^{\mathrm{b}}$ & $23.8 \pm 1.2^{\mathrm{a}}$ \\
\hline $\mathrm{C} 22: 6 \mathrm{n}-3$ & $29.5 \pm 8.0^{\mathrm{a}}$ & $3.9 \pm 0.0^{\mathrm{c}}$ & $11.9 \pm 0.2^{\mathrm{b}}$ & Proline, PRO & $3.2 \pm 0.2 \mathrm{c}$ & $6.9 \pm 0.5 \mathrm{a}$ & $4.9 \pm 0.3 b$ \\
\hline$\sum$ PUFA & $44.2 \pm 12.4$ & $27.8 \pm 5.5$ & $25.6 \pm 4.0$ & Aspartic acid, ASP & $8.0 \pm 1.6$ & $8.1 \pm 0.5$ & $7.2 \pm 3.8$ \\
\hline$\sum \mathrm{n}-3$ & $41.6 \pm 12.3$ & $10.2 \pm 1.5$ & $20.0 \pm 5.0$ & Glutamic acid, GLU & $7.1 \pm 1.3$ & $12.2 \pm 2.3$ & $9.0 \pm 2.6$ \\
\hline \multirow{2}{*}{ 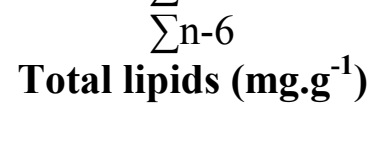 } & $2.5 \pm 0.7$ & $17.6 \pm 8.6$ & $5.6 \pm 2.2$ & Glutamine, GLN & $0.3 \pm 0.0$ & $0.4 \pm 0.1$ & $0.6 \pm 0.4$ \\
\hline & $308.9 \pm 76.8^{\mathrm{a}}$ & $90.2 \pm 5.2^{\mathrm{c}}$ & $210.1 \pm 8.6^{\mathrm{b}}$ & $\begin{array}{c}\text { Tyrosine, TYR } \\
\text { Allo-isoleucine, AILE }\end{array}$ & $\begin{array}{l}0.8 \pm 0.9 \\
3.8 \pm 0.1\end{array}$ & $\begin{array}{l}1.2 \pm 0.2 \\
5.0 \pm 0.0\end{array}$ & $\begin{array}{l}0.9 \pm 0.4 \\
4.6 \pm 0.5\end{array}$ \\
\hline $\begin{array}{c}\text { Vitamin A } \\
\mathrm{VA}_{1}\left(\begin{array}{c}\text { (sum of retinol }) \\
\left(\mathrm{mg} \cdot \mathrm{g}^{-1}\right)\end{array}\right.\end{array}$ & 0.12 & - & - & $\Sigma$ Protein $\left(\mathrm{mg}^{-g^{-1}}\right)$ & $153.0 \pm 10.2^{\mathrm{b}}$ & $450.0 \pm 62.0^{\mathrm{a}}$ & $417.0 \pm 78.8^{\circ}$ \\
\hline \multirow{4}{*}{$\begin{array}{l}\quad\left(\mathrm{mg} \cdot \mathrm{g}^{-1}\right) \\
\mathrm{VA}_{2}(\text { didehydro-all- } \\
\text { trans-retinol })\left(\mathrm{mg} \cdot \mathrm{g}^{-1}\right)\end{array}$} & 0.05 & - & - & $\Sigma$ Essential $\left(\mathrm{mg.g}^{-1}\right)$ & $43.2 \pm 1.6^{\mathrm{b}}$ & $92.6 \pm 13.1^{\mathrm{a}}$ & $107.7 \pm 17.3^{2}$ \\
\hline & & & & $\Sigma$ Acidic $(\mathrm{mg} / \mathrm{g})$ & $19.7 \pm 4.9$ & $71.5 \pm 25.0$ & $67.8 \pm 38.0$ \\
\hline & & & & $\Sigma$ Basic $(\mathrm{mg} / \mathrm{g})$ & $11.9 \pm 1.5$ & $29.0 \pm 2.5$ & $26.8 \pm 6.5$ \\
\hline & & & & $\Sigma$ Aromatic $(\mathrm{mg} / \mathrm{g})$ & $8.2 \pm 1.8$ & $20.6 \pm 2.3$ & $20.2 \pm 2.9$ \\
\hline
\end{tabular}

$\dagger:$ Includes $\mathrm{C} 15: 0, \mathrm{C} 17: 0, \mathrm{C} 20: 0, \mathrm{C} 21: 0$ and $\mathrm{C} 24: 0$ with percentages $<0.5 \%$ \#: Includes C14:1, C17:1, C24:1 n-9 with percentages $\leq 1.5 \%$

5: Includes C18: 4 n-3, C20:3 n-3, C18:3 n-6, C20:3 n-6, C20:4 n-6 < 1\%
Amino acids whose percentages were $<1 \%$ were not listed but included when calculating total protein, essential, acidic, basic, and aromatic

- Includes tryptophan (TRP)

${ }^{+}$: Includes asparagine, ornithine, hydroxylysine, aminoisobutyric acid, glycine-proline, $\alpha$-aminoadipic acid, $\alpha$ aminopimelic acid, proline-hydroxyproline, amino-n-butyric acid, thioproline, hydroxyproline, cystathionine, cystine. 


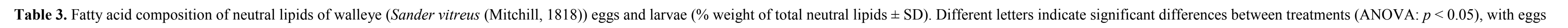
and larvae being tested separately (EXP-9Y, EXP-5Y, COM-9Y, COM-5Y, W; see Table 1 caption for treatment abbreviations).

\begin{tabular}{|c|c|c|c|c|c|c|c|c|c|c|}
\hline \multirow{3}{*}{$\begin{array}{c}\text { Neutral } \\
\text { FAs }\end{array}$} & \multicolumn{5}{|c|}{ Eggs } & \multicolumn{5}{|c|}{ Larvae } \\
\hline & \multicolumn{10}{|c|}{ Treatments } \\
\hline & EXP-5Y & EXP-9Y & COM-5Y & COM-9Y & W & EXP-5Y & EXP-9Y & COM-5Y & COM-9Y & W \\
\hline C14:0 & $2.3 \pm 0.2$ & $2.2 \pm 0.1$ & $2.4 \pm 0.1$ & $2.2 \pm 0.1$ & $2.2 \pm 0.0$ & $2.3 \pm 0.1$ & $2.3 \pm 0.1$ & $2.3 \pm 0.1$ & $2.2 \pm 0.1$ & $2.2 \pm 0.2$ \\
\hline C16:0 & $10.0 \pm 0.5$ & $9.3 \pm 0.4$ & $9.6 \pm 0.3$ & $9.3 \pm 0.3$ & $8.6 \pm 0.4$ & $9.4 \pm 0.6$ & $9.9 \pm 0.9$ & $9.8 \pm 0.4$ & $9.7 \pm 1.3$ & $9.3 \pm 0.4$ \\
\hline C18:0 & $1.10 \pm 0.3$ & $0.9 \pm 0.2$ & $0.9 \pm 0.1$ & $0.8 \pm 0.2$ & $0.9 \pm 0.2$ & $1.0 \pm 0.1$ & $1.2 \pm 0.4$ & $1.1 \pm 0.3$ & $1.3 \pm 0.7$ & $1.6 \pm 0.2$ \\
\hline SFAs $\dagger$ & $14.5 \pm 0.2$ & $13.2 \pm 0.1$ & $13.6 \pm 0.1$ & $13.1 \pm 0.1$ & $12.4 \pm 0.1$ & $13.8 \pm 0.2$ & $14.6 \pm 0.3$ & $14.4 \pm 0.1$ & $14.8 \pm 0.3$ & $14.5 \pm 0.1$ \\
\hline C16: 1 & $12.5 \pm 1.2$ & $12.2 \pm 0.2$ & $13.2 \pm 0.2$ & $12.4 \pm 0.4$ & $16.1 \pm 1.5$ & $12.2 \pm 0.6$ & $12.1 \pm 0.4$ & $12.4 \pm 0.4$ & $11.6 \pm 0.7$ & $15.0 \pm 1.9$ \\
\hline C17:1 & $0.7 \pm 0.1$ & $0.7 \pm 0.0$ & $0.7 \pm 0.0$ & $0.7 \pm 0.0$ & $1.0 \pm 0.1$ & $0.7 \pm 0.0$ & $0.7 \pm 0.1$ & $0.7 \pm 0.0$ & $0.8 \pm 0.1$ & $1.1 \pm 0.1$ \\
\hline C18:1 n-9 & $24.1 \pm 1.8$ & $25.6 \pm 1.5$ & $24.2 \pm 0.8$ & $25.6 \pm 0.8$ & $25.3 \pm 0.6$ & $23.6 \pm 0.6$ & $27.2 \pm 0.6$ & $23.3 \pm 0.8$ & $24.1 \pm 1.2$ & $26.7 \pm 1.6$ \\
\hline C20:1 n-9 & $2.8 \pm 0.3$ & $3.4 \pm 0.3$ & $2.6 \pm 0.1$ & $3.2 \pm 0.1$ & $0.3 \pm 0.0$ & $2.8 \pm 0.2$ & $3.9 \pm 0.1$ & $2.7 \pm 0.2$ & $3.0 \pm 0.5$ & $0.4 \pm 0.1$ \\
\hline C22:1 n-9 & $0.5 \pm 0.0$ & $0.7 \pm 0.1$ & $0.5 \pm 0.0$ & $0.6 \pm 0.0$ & $0.0 \pm 0.0$ & $0.5 \pm 0.0$ & $0.8 \pm 0.1$ & $0.5 \pm 0.1$ & $0.8 \pm 0.1$ & $0.0 \pm 0.0$ \\
\hline MUFAst & $41.0 \pm 0.7$ & $43.0 \pm 0.5$ & $41.5 \pm 0.3$ & $43.0 \pm 0.3$ & $43.2 \pm 0.5$ & $40.3 \pm 0.2$ & $45.2 \pm 0.3$ & $40.1 \pm 0.1$ & $40.9 \pm 0.4$ & $44.0 \pm 0.1$ \\
\hline C18:2 n-6 & $2.4 \pm 0.3^{\mathrm{b}}$ & $2.6 \pm 0.4^{\mathbf{b}}$ & $2.9 \pm 0.8^{\mathbf{b}}$ & $2.6 \pm 0.4^{\mathrm{b}}$ & $5.6 \pm 0.3^{\mathrm{a}}$ & $2.3 \pm 0.3^{\mathrm{b}}$ & $2.9 \pm 0.1^{\mathrm{b}}$ & $2.9 \pm 0.4^{\mathrm{b}}$ & $2.5 \pm 0.1^{\mathrm{b}}$ & $5.5 \pm 0.4^{\mathrm{a}}$ \\
\hline C18:3 n-6 & $0.1 \pm 0.0$ & $0.2 \pm 0.0$ & $0.1 \pm 0.0$ & $0.1 \pm 0.0$ & $0.5 \pm 0.0$ & $0.2 \pm 0.0$ & $0.2 \pm 0.1$ & $0.2 \pm 0.1$ & $0.2 \pm 0.0$ & $0.6 \pm 0.1$ \\
\hline C20:3 n-6 & $0.1 \pm 0.0$ & $0.1 \pm 0.0$ & $0.1 \pm 0.0$ & $0.1 \pm 0.0$ & $0.3 \pm 0.0$ & $0.1 \pm 0.0$ & $0.2 \pm 0.0$ & $0.1 \pm 0.0$ & $0.2 \pm 0.0$ & $0.3 \pm 0.0$ \\
\hline C20:4 n-6 & $0.1 \pm 0.0$ & $0.1 \pm 0.0$ & $0.1 \pm 0.0$ & $0.1 \pm 0.0$ & $0.3 \pm 0.0$ & $0.1 \pm 0.0$ & $0.1 \pm 0.0$ & $0.1 \pm 0.0$ & $0.0 \pm 0.0$ & $0.3 \pm 0.0$ \\
\hline C18:3 n-3 & $0.9 \pm 0.1^{\mathbf{b}}$ & $0.8 \pm 0.0^{\mathbf{b}}$ & $0.9 \pm 0.1^{\mathrm{b}}$ & $0.8 \pm 0.1^{\mathbf{b}}$ & $5.0 \pm 0.3^{\mathrm{a}}$ & $0.9 \pm 0.1^{\mathbf{b}}$ & $0.9 \pm 0.1^{\mathbf{b}}$ & $0.9 \pm 0.1^{\mathrm{b}}$ & $0.9 \pm 0.0^{\mathbf{b}}$ & $4.9 \pm 0.5^{\mathrm{a}}$ \\
\hline C18:4 n-3 & $0.8 \pm 0.0$ & $0.6 \pm 0.0$ & $0.8 \pm 0.0$ & $0.7 \pm 0.0$ & $2.1 \pm 0.2$ & $0.7 \pm 0.0$ & $0.6 \pm 0.0$ & $0.7 \pm 0.1$ & $0.8 \pm 0.1$ & $1.6 \pm 0.1$ \\
\hline C20:3 n-3 & $0.5 \pm 0.0^{\mathbf{b}}$ & $0.6 \pm 0.0^{\mathbf{b}}$ & $0.5 \pm 0.0^{\mathbf{b}}$ & $0.6 \pm 0.1^{\mathrm{b}}$ & $2.8 \pm 0.4^{\mathrm{a}}$ & $0.6 \pm 0.0^{\mathbf{b}}$ & $0.6 \pm 0.4^{\mathrm{b}}$ & $0.6 \pm 0.0^{\mathrm{b}}$ & $0.8 \pm 0.1^{\mathbf{b}}$ & $3.1 \pm 0.4^{\mathrm{a}}$ \\
\hline C20:5 n-3 & $7.6 \pm 0.8$ & $7.4 \pm 0.2$ & $8.1 \pm 0.1$ & $7.7 \pm 0.6$ & $4.6 \pm 0.2$ & $8.0 \pm 0.3$ & $7.0 \pm 0.3$ & $8.0 \pm 0.4$ & $7.1 \pm 0.3$ & $4.2 \pm 0.5$ \\
\hline C22:6 n-3 & $31.3 \pm 1.4^{\mathrm{a}}$ & $30.6 \pm 3.1^{\mathrm{a}}$ & $30.7 \pm 0.8^{\mathrm{a}}$ & $30.3 \pm 1.7^{\mathrm{a}}$ & $22.2 \pm 2.5^{\mathbf{b}}$ & $32.2 \pm 1.0^{\mathrm{a}}$ & $26.3 \pm 2.0^{\mathrm{a}}$ & $30.4 \pm 1.5^{\mathrm{a}}$ & $29.9 \pm 1.1^{\mathrm{a}}$ & $19.1 \pm 2.1^{\mathbf{b}}$ \\
\hline PUFAst & $44.0 \pm 0.5$ & $43.1 \pm 1.0$ & $44.3 \pm 0.3$ & $43.2 \pm 0.5$ & $43.4 \pm 0.8$ & $45.3 \pm 0.3$ & $39.0 \pm 0.6$ & $44.2 \pm 0.5$ & $42.4 \pm 0.4$ & $39.7 \pm 0.7$ \\
\hline Total lipids & $191 \pm 45.6$ & $117 \pm 19.6$ & $120 \pm 25.7$ & $114 \pm 63.7$ & $144 \pm 71.2$ & $162 \pm 24.5^{\mathrm{a}}$ & $161 \pm 41.5^{\mathrm{a}}$ & $115 \pm 31.4^{\mathbf{a b}}$ & $97 \pm 65.1^{\mathbf{a b}}$ & $71 \pm 39.4^{\mathbf{b}}$ \\
\hline
\end{tabular}

$\dagger:$ Includes C12:0, C15: 0, C17:0, C20:0, C22:0, and C24:0 with percentages $<0.5 \%$, + : Includes C14:1 and C24:1 n-9 with percentages $\leq 0.3 \%$, : Includes C20:2 with percentages $<0.2 \%$ 


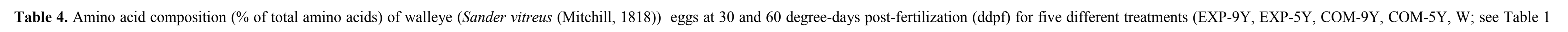
caption for treatment abbreviations). Means in a row with different letters are significantly different (treatments $\mathrm{x}$ ddpf: $p<0.05$ ).

\begin{tabular}{|c|c|c|c|c|c|c|c|c|c|c|}
\hline \multicolumn{11}{|l|}{ Amino acids in eggs } \\
\hline \multirow{2}{*}{$\begin{array}{c}\text { Degree days post fertilization } \\
\text { Treatments }\end{array}$} & \multicolumn{5}{|c|}{$30 \mathrm{DD}$} & \multicolumn{5}{|c|}{$60 \mathrm{DD}$} \\
\hline & EXP-5Y & EXP-9Y & COM-5Y & COM-9Y & $\mathrm{W}$ & EXP-5Y & EXP-9Y & COM-5Y & COM-9Y & $\mathrm{W}$ \\
\hline \multicolumn{11}{|c|}{ Essential amino acids ${ }^{*}$} \\
\hline Valine, VAL & $8.0 \pm 0.1$ & $8.4 \pm 0.1$ & $8.8 \pm 0.0$ & $8.5 \pm 0.0$ & $6.6 \pm 0.7$ & $8.0 \pm 0.1$ & $9.6 \pm 0.2$ & $9.0 \pm 0.1$ & $8.0 \pm 0.1$ & $8.6 \pm 0.2$ \\
\hline Leucine, LEU & $11.0 \pm 0.1$ & $10.9 \pm 0.1$ & $11.4 \pm 0.0$ & $10.2 \pm 0.0$ & $8.5 \pm 0.7$ & $11.4 \pm 0.2$ & $11.4 \pm 0.3$ & $9.7 \pm 0.2$ & $12.3 \pm 0.2$ & $10.6 \pm 0.3$ \\
\hline Isoleucine, ILE & $6.5 \pm 0.0$ & $6.0 \pm 0.0$ & $6.9 \pm 0.0$ & $7.1 \pm 0.0$ & $5.3 \pm 0.3$ & $6.6 \pm 0.1$ & $6.7 \pm 0.1$ & $6.3 \pm 0.1$ & $6.6 \pm 0.1$ & $7.6 \pm 0.2$ \\
\hline Threonine, THR & $5.5 \pm 0.0$ & $7.3 \pm 0.0$ & $7.4 \pm 0.0$ & $6.2 \pm 0.0$ & $4.3 \pm 0.6$ & $5.3 \pm 0.0$ & $6.4 \pm 0.1$ & $7.6 \pm 0.1$ & $5.5 \pm 0.0$ & $5.4 \pm 0.2$ \\
\hline Histidine, HIS & $2.5 \pm 0.0$ & $1.3 \pm 0.0$ & $0.4 \pm 0.0$ & $1.2 \pm 0.0$ & $1.7 \pm 0.0$ & $1.6 \pm 0.1$ & $1.0 \pm 0.2$ & $0.5 \pm 0.1$ & $1.4 \pm 0.0$ & $1.7 \pm 0.0$ \\
\hline Methionine, MET & $3.1 \pm 0.0^{\mathrm{a}}$ & $2.7 \pm 0.0^{\mathrm{b}}$ & $2.3 \pm 0.0^{\mathrm{cd}}$ & $2.0 \pm 0.0^{\mathrm{e}}$ & $0.1 \pm 0.1^{\mathrm{f}}$ & $3.1 \pm 0.0^{\mathrm{a}}$ & $2.1 \pm 0.0^{\mathrm{e}}$ & $2.3 \pm 0.0^{\mathrm{cd}}$ & $2.5 \pm 0.0^{\mathrm{c}}$ & $0.1 \pm 0.0^{\mathrm{f}}$ \\
\hline Phenylalanine, PHE & $3.6 \pm 0.0$ & $3.8 \pm 0.0$ & $4.1 \pm 0.0$ & $3.7 \pm 0.0$ & $3.6 \pm 0.4$ & $4.7 \pm 0.0$ & $3.6 \pm 0.0$ & $3.5 \pm 0.0$ & $4.5 \pm 0.0$ & $4.7 \pm 0.1$ \\
\hline Lysine, LYS & $10.9 \pm 0.0$ & $6.5 \pm 0.1$ & $4.9 \pm 0.0$ & $5.9 \pm 0.0$ & $7.2 \pm 0.7$ & $12.5 \pm 0.1$ & $4.1 \pm 0.2$ & $4.0 \pm 0.1$ & $9.0 \pm 0.0$ & $5.7 \pm 0.1$ \\
\hline \multicolumn{11}{|c|}{ Non-essential amino acids ${ }^{+}$} \\
\hline Alanine, ALA & $11.9 \pm 0.1$ & $12.4 \pm 0.1$ & $14.9 \pm 0.0$ & $12.2 \pm 0.1$ & $11.9 \pm 1.5$ & $11.7 \pm 0.2$ & $18.9 \pm 0.7$ & $14.3 \pm 0.4$ & $12.7 \pm 0.2$ & $14.9 \pm 0.5$ \\
\hline Glycine, GLY & $4.9 \pm 0.0$ & $6.1 \pm 0.0$ & $6.5 \pm 0.0$ & $5.1 \pm 0.0$ & $5.7 \pm 0.0$ & $4.5 \pm 0.0$ & $8.3 \pm 0.3$ & $6.7 \pm 0.2$ & $4.5 \pm 0.0$ & $6.1 \pm 0.2$ \\
\hline Serine, SER & $6.6 \pm 0.0^{\mathrm{de}}$ & $7.8 \pm 0.0^{\mathrm{bc}}$ & $8.7 \pm 0.0^{\mathrm{ab}}$ & $9.9 \pm 0.0^{\mathrm{a}}$ & $5.8 \pm 0.9^{\mathrm{e}}$ & $6.6 \pm 0.1^{\text {de }}$ & $2.7 \pm 0.2^{\mathrm{f}}$ & $7.7 \pm 0.1 b^{\mathrm{c}}$ & $7.2 \pm 0.0^{\text {cd }}$ & $0.1 \pm 0.2^{\mathrm{g}}$ \\
\hline Proline, PRO & $4.8 \pm 0.0$ & $6.9 \pm 0.1$ & $8.4 \pm 0.0$ & $5.5 \pm 0.0$ & $4.4 \pm 0.3$ & $5.7 \pm 0.0$ & $10.0 \pm 0.3$ & $7.5 \pm 0.0$ & $5.6 \pm 0.0$ & $5.5 \pm 0.0$ \\
\hline Aspartic acid, ASP & $7.6 \pm 0.0$ & $7.2 \pm 0.0$ & $5.9 \pm 0.0$ & $8.5 \pm 0.0$ & $10.2 \pm 2.6$ & $6.3 \pm 0.0$ & $5.2 \pm 0.0$ & $8.7 \pm 0.0$ & $6.9 \pm 0.0$ & $9.7 \pm 0.0$ \\
\hline Glutamic acid, GLU & $9.9 \pm 0.0$ & $8.2 \pm 0.0$ & $7.6 \pm 0.0$ & $9.4 \pm 0.0$ & $12.5 \pm 0.7$ & $7.5 \pm 0.0$ & $2.6 \pm 0.0$ & $7.9 \pm 0.0$ & $7.6 \pm 0.0$ & $13.4 \pm 0.1$ \\
\hline Tyrosine, TYR & $0.2 \pm 0.0$ & $1.2 \pm 0.0$ & $0.1 \pm 0.0$ & $2.6 \pm 0.0$ & $3.4 \pm 0.2$ & $0.4 \pm 0.0$ & $0.8 \pm 0.1$ & $0.4 \pm 0.0$ & $3.4 \pm 0.0$ & $2.9 \pm 0.7$ \\
\hline Kessential $\left(\mathrm{mg} \cdot \mathrm{g}^{-1}\right)$ & $19.5 \pm 1.9^{\mathrm{a}}$ & $9.5 \pm 1.4^{\mathrm{ab}}$ & $13.9 \pm 1.8^{\mathrm{ab}}$ & $7.9 \pm 2.0^{\mathrm{b}}$ & $9.9 \pm 3.2^{\mathrm{ab}}$ & $12.7 \pm 4.0^{\mathrm{ab}}$ & $19.2 \pm 1.0^{\mathrm{ab}}$ & $12.9 \pm 5.6^{\mathrm{ab}}$ & $7.4 \pm 1.1^{\mathrm{b}}$ & $17.4 \pm 5.0^{\mathrm{ab}}$ \\
\hline Total protein $\left(\mathrm{mg} \cdot \mathrm{g}^{-1}\right)$ & $35.0 \pm 2.4^{\mathrm{ab}}$ & $18.9 \pm 3.4^{\mathrm{ab}}$ & $27.0 \pm 3.7^{\mathrm{ab}}$ & $16.6 \pm 4.1^{\mathrm{ab}}$ & $22.4 \pm 6.1^{\mathrm{ab}}$ & $23.4 \pm 5.2^{\mathrm{ab}}$ & $38.7 \pm 2.7^{\mathrm{a}}$ & $27.5 \pm 12.0^{\mathrm{ab}}$ & $14.8 \pm 2.9^{\mathrm{b}}$ & $37.2 \pm 10.0^{\text {ab }}$ \\
\hline
\end{tabular}

Amino acids whose percentages were $<1 \%$ were not listed but included when calculating total protein and essential

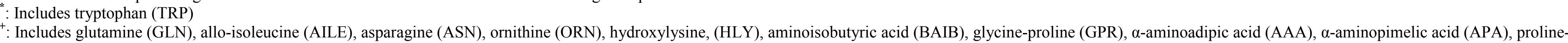
hydroxyproline (PHP), amino-n-butyric acid (ABA), thioproline (TPR), hydroxyproline (HYP), cystathionine (CTH), cystine (C-C) 
Table 5. Amino acid composition (\% of total amino acids) of walleye (Sander vitreus (Mitchill, 1818)) larvae for five different treatments (EXP-9Y, EXP-5Y, COM-9Y, COM-5Y, W; see Table 1 caption for treatment abbreviations). Means in a row with different letters are significantly different (ANOVA: $p<0.05)$.

\begin{tabular}{|c|c|c|c|c|c|}
\hline \multicolumn{6}{|l|}{ Amino acids in larvae } \\
\hline \multirow[t]{2}{*}{ Treatments } & EXP-5Y & EXP-9Y & $\mathrm{COM}-5 \mathrm{Y}$ & COM-9Y & $\mathrm{W}$ \\
\hline & \multicolumn{3}{|c|}{ Essential amino acids" } & & \\
\hline Valine, VAL & $7.6 \pm 0.2$ & $7.7 \pm 0.4$ & $7.5 \pm 0.2$ & $7.4 \pm 0.4$ & $7.5 \pm 0.6$ \\
\hline Leucine, LEU & $11.3 \pm 1.4$ & $10.1 \pm 0.6$ & $10.5 \pm 1.0$ & $8.8 \pm 0.2$ & $9.7 \pm 0.6$ \\
\hline Isoleucine, ILE & $5.8 \pm 0.0$ & $5.7 \pm 0.3$ & $5.7 \pm 0.0$ & $6.2 \pm 0.4$ & $5.7 \pm 0.5$ \\
\hline Threonine, THR & $5.5 \pm 0.3$ & $7.1 \pm 0.7$ & $5.9 \pm 0.4$ & $7.9 \pm 0.3$ & $5.2 \pm 0.4$ \\
\hline Histidine, HIS & $1.4 \pm 1.1$ & $1.3 \pm 0.5$ & $1.3 \pm 0.4$ & $1.6 \pm 0.4$ & $2.3 \pm 0.2$ \\
\hline Methionine, MET & $2.8 \pm 0.7^{\mathrm{a}}$ & $2.8 \pm 0.2^{\mathrm{a}}$ & $2.9 \pm 0.4^{\mathrm{a}}$ & $1.9 \pm 0.8^{\mathrm{b}}$ & $0.3 \pm 0.4^{\mathrm{c}}$ \\
\hline Phenylalanine, PHE & $3.8 \pm 0.6$ & $3.3 \pm 0.1$ & $3.9 \pm 0.3$ & $3.0 \pm 0.0$ & $4.8 \pm 0.2$ \\
\hline \multirow[t]{2}{*}{ Lysine, LYS } & $7.9 \pm 0.1$ & $4.8 \pm 0.2$ & $8.0 \pm 1.8$ & $4.7 \pm 0.2$ & $6.2 \pm 0.2$ \\
\hline & \multicolumn{3}{|c|}{ Non essential amino acids ${ }^{+}$} & & \\
\hline Alanine, ALA & $16.3 \pm 3.1$ & $10.6 \pm 1.3$ & $11.9 \pm 1.2$ & $10.8 \pm 1.0$ & $11.4 \pm 1.0$ \\
\hline Glycine, GLY & $5.9 \pm 1.1$ & $8.0 \pm 0.6$ & $5.5 \pm 1.1$ & $5.7 \pm 0.8$ & $8.4 \pm 0.8$ \\
\hline Serine, SER & $5.4 \pm 1.8^{\mathfrak{c}}$ & $7.6 \pm 0.4^{b}$ & $8.4 \pm 0.1^{\mathrm{b}}$ & $10.1 \pm 0.9^{\mathrm{a}}$ & $0.2 \pm 0.1^{\mathrm{d}}$ \\
\hline Proline, PRO & $5.2 \pm 0.6$ & $5.5 \pm 0.5$ & $5.5 \pm 0.3$ & $5.2 \pm 0.1$ & $5.4 \pm 0.8$ \\
\hline Aspartic acid, ASP & $8.5 \pm 1.7$ & $8.8 \pm 1.5$ & $8.3 \pm 0.8$ & $8.9 \pm 0.8$ & $10.4 \pm 0.9$ \\
\hline Glutamic acid, GLU & $8.1 \pm 4.1^{b}$ & $9.7 \pm 2.1^{\mathbf{b}}$ & $9.8 \pm 1.3^{\mathbf{b}}$ & $8.6 \pm 0.1^{\mathbf{b}}$ & $13.4 \pm 1.9^{\mathrm{a}}$ \\
\hline Tyrosine, TYR & $1.9 \pm 1.8^{b}$ & $0.8 \pm 0.5^{\mathbf{b}}$ & $2.9 \pm 0.5^{\mathbf{b}}$ & $2.6 \pm 0.2^{\mathbf{b}}$ & $3.6 \pm 0.1^{\mathrm{a}}$ \\
\hline Cystathionine, CTH & $0.2 \pm 0.0$ & $0.9 \pm 0.5$ & $0.2 \pm 0.0$ & $1.2 \pm 0.5$ & $1.4 \pm 1.8$ \\
\hline Cystine, C-C & $0.3 \pm 0.0$ & $1.0 \pm 0.6$ & $0.3 \pm 0.0$ & $1.4 \pm 0.6$ & $0.8 \pm 0.1$ \\
\hline Eessential (mg. $\left.\mathrm{g}^{-1}\right)$ & $14.2 \pm 0.0$ & $12.2 \pm 12.1$ & $12.4 \pm 0.3$ & $3.8 \pm 0.6$ & $15.7 \pm 7.4$ \\
\hline Total protein $\left(\mathrm{mg} . \mathrm{g}^{-1}\right)$ & $24.5 \pm 2.4$ & $40.3 \pm 3.2$ & $23.8 \pm 1.1$ & $20.8 \pm 9.4$ & $34.1 \pm 15.5$ \\
\hline
\end{tabular}

Amino acids whose percentages were $<1 \%$ were not listed but are included when calculating total protein and essential, acidic, basic, and aromatic amino acids.

*: Includes Tryptophan (TRP)

${ }^{+}:$Includes asparagine (ASN), ornithine (ORN), hydroxylysine, (HLY), aminoisobutyric acid (BAIB), glycine-proline (GPR), $\alpha$-aminoadipic acid (AAA), $\alpha$-aminopimelic acid (APA), proline-hydroxyproline (PHP), amino-n-butyric acid (ABA), thioproline (TPR), hydroxyproline (HYP), allo-isoleucine (AILE), glutamine $(\mathrm{GLN})$ 


\section{Figure captions}

Fig. 1. Non-metric multi-dimensional scaling of the Bray-Curtis similarity matrix based on the relative abundance of neutral (upper) and polar (lower) fatty acid profiles associated with eggs (left) and larvae (right). Neutral fatty acid profiles varied as a function of treatment (experimental - 9 years old [EXP-9Y], experimental - 5 years old [EXP-5Y], commercial - 9 years old [COM9Y], commercial - 5 years old [COM-5Y], and wild [W]). Polar fatty acid profiles varied as a function of treatment and degree-days post fertilization (ddpf) (30 and $60 \mathrm{ddpf}$ for eggs; 200 and 230 ddpf for larvae). The arrows represent the fatty acid responsible for most of the variation.

Fig. 2. Composition of the most abundant fatty acids in polar lipids (\% weight of total polar lipids \pm SD) in eggs and larvae. Different letters indicate statistically significant differences between treatments (EXP-9Y, EXP-5Y, COM-9Y, COM-5Y, W; see Figure 1 caption for treatment abbreviations).

Fig. 3. Composition of vitamin A (Vitamin $A_{1}$ : all-trans-ROH [left] and vitamin $A_{2}$ : dehydro$\mathrm{ROH}$ [right]) in eggs at 30 degree-days post fertilization (mean $\pm \mathrm{SD}$ ). Different letters indicate statistically significant differences among treatments (EXP-9Y, EXP-5Y, COM-9Y, COM-5Y, W; see Figure 1 caption for treatment abbreviations).

Fig. 4. Content of vitamin $\mathrm{A}_{1}$ (all-trans-ROH; left) and vitamin $\mathrm{A}_{2}$ (dehydro-ROH; right) in eggs in relation to hatching success. 


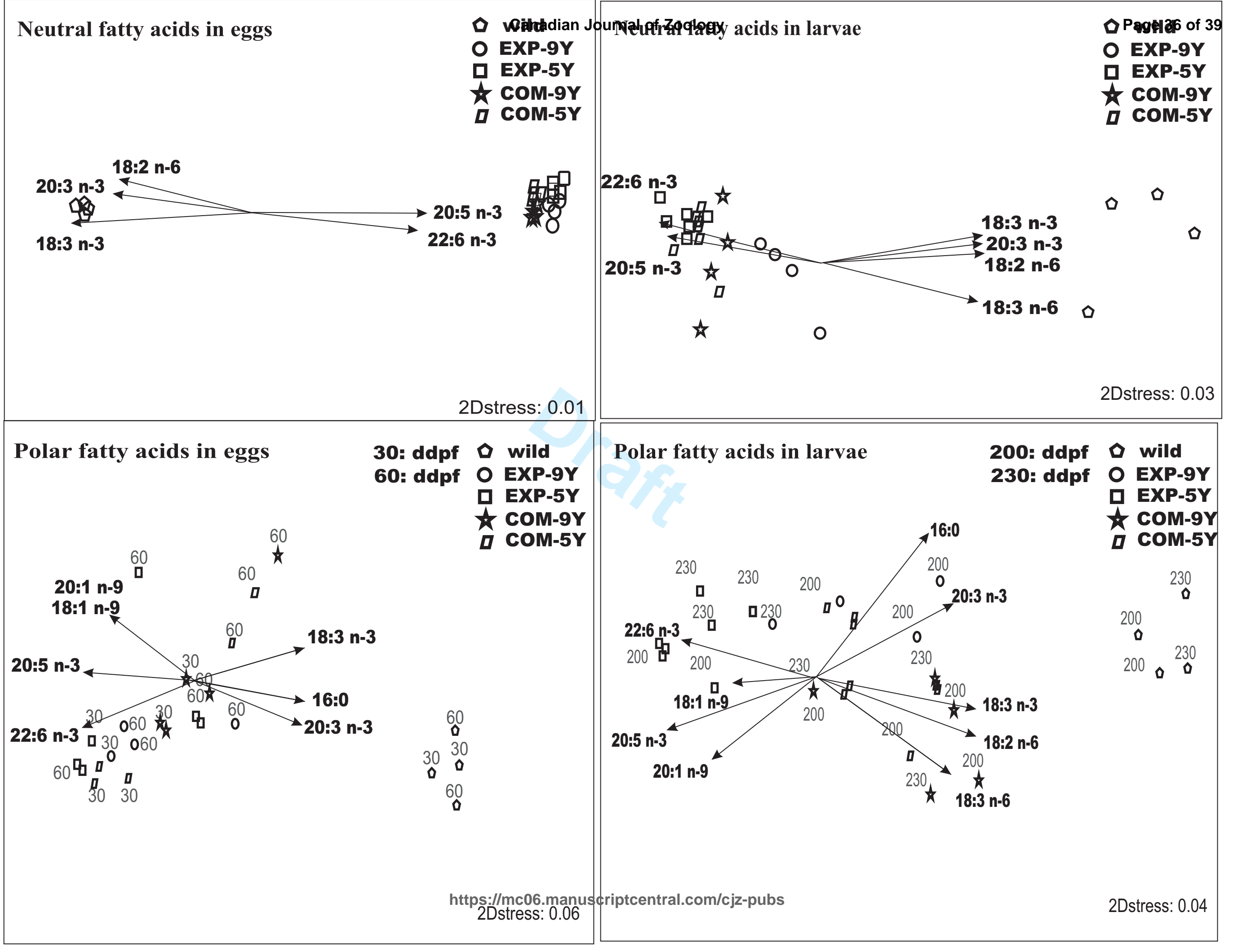




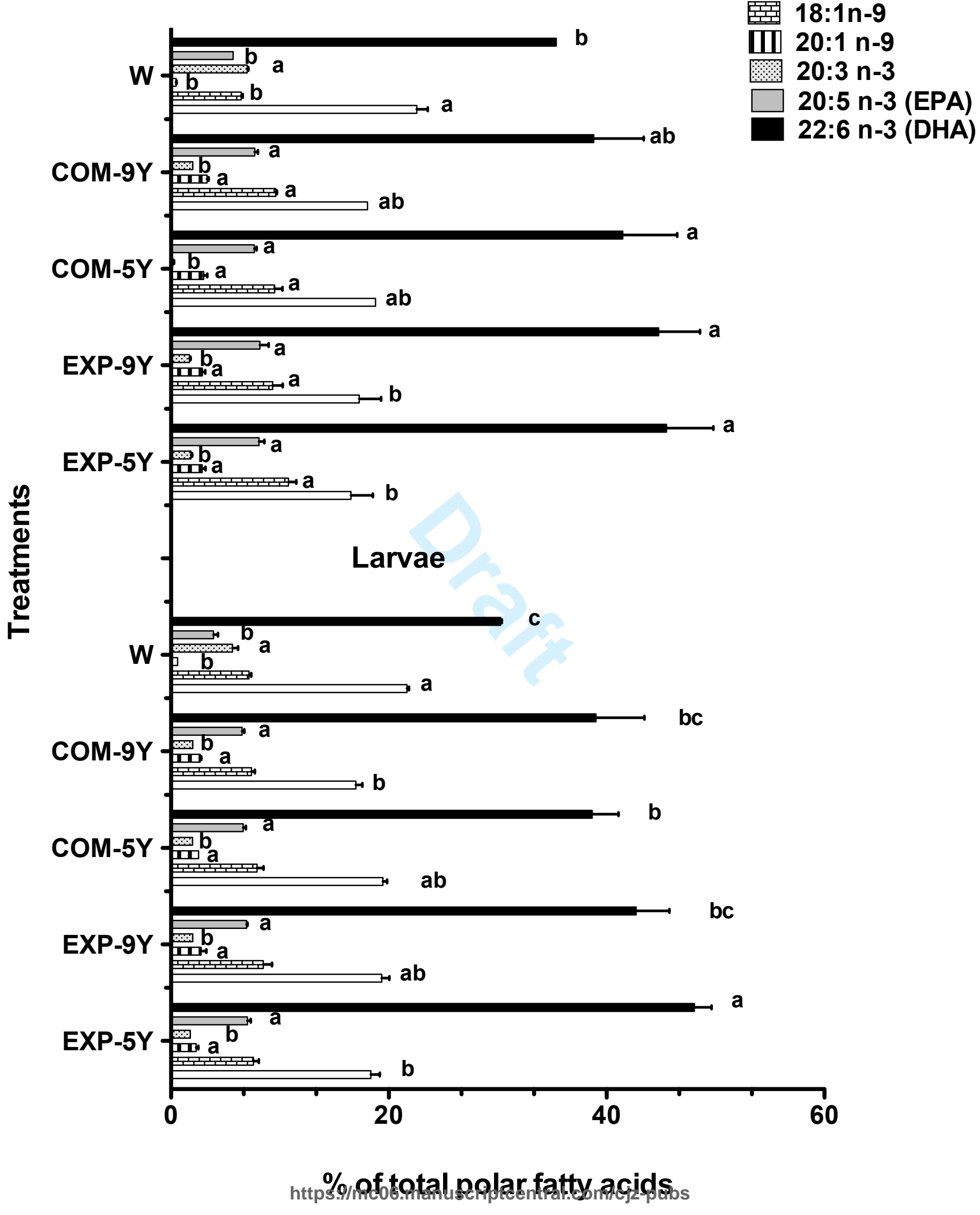




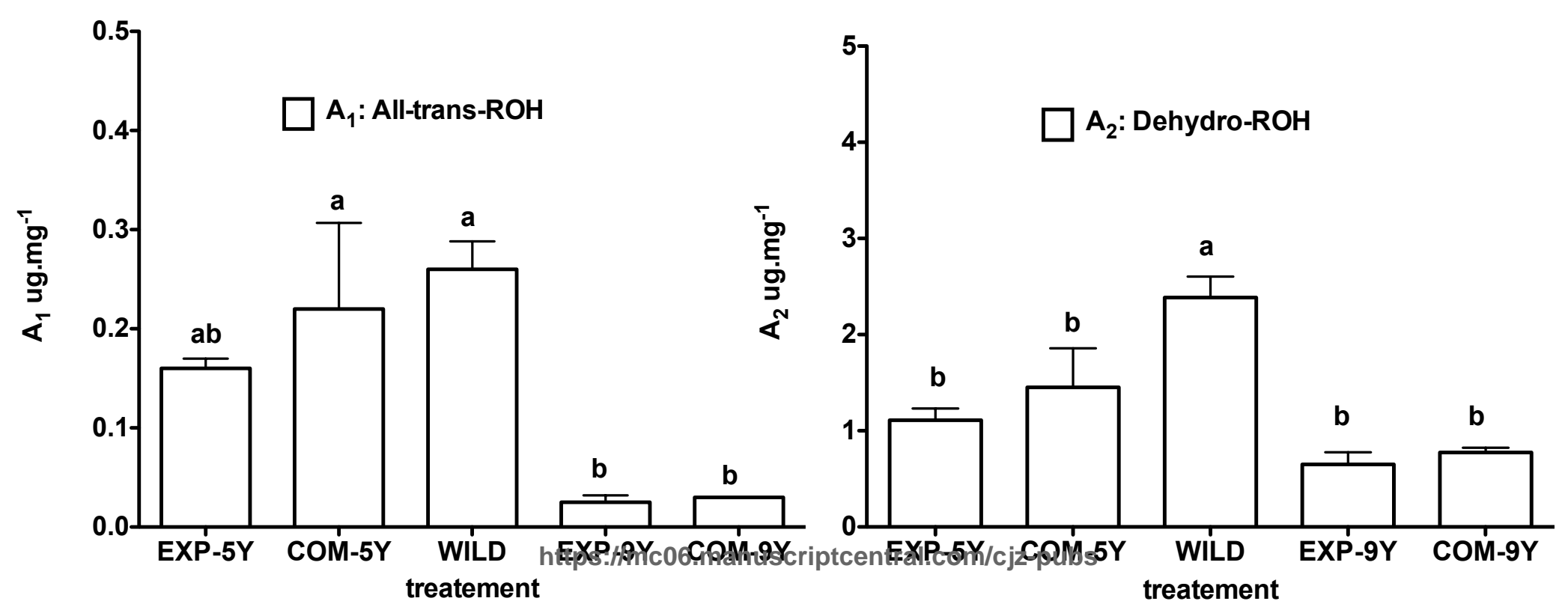




\section{Page 39 of 39}

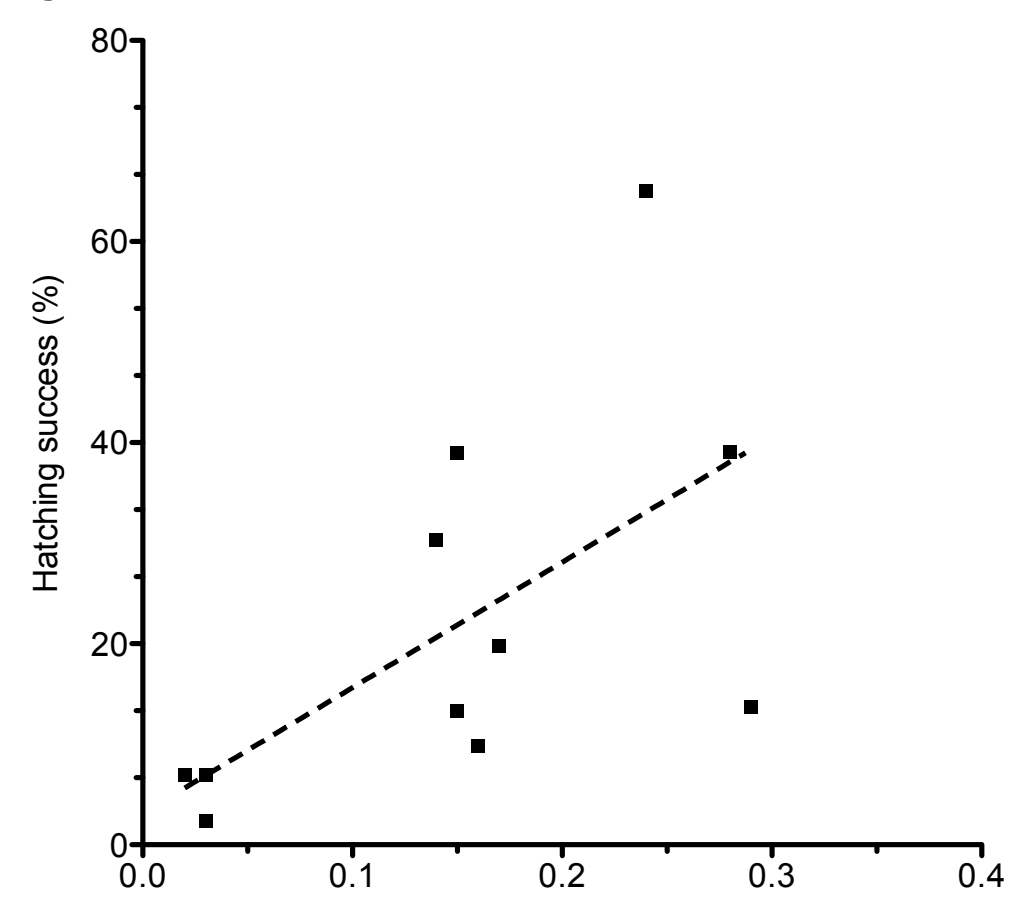

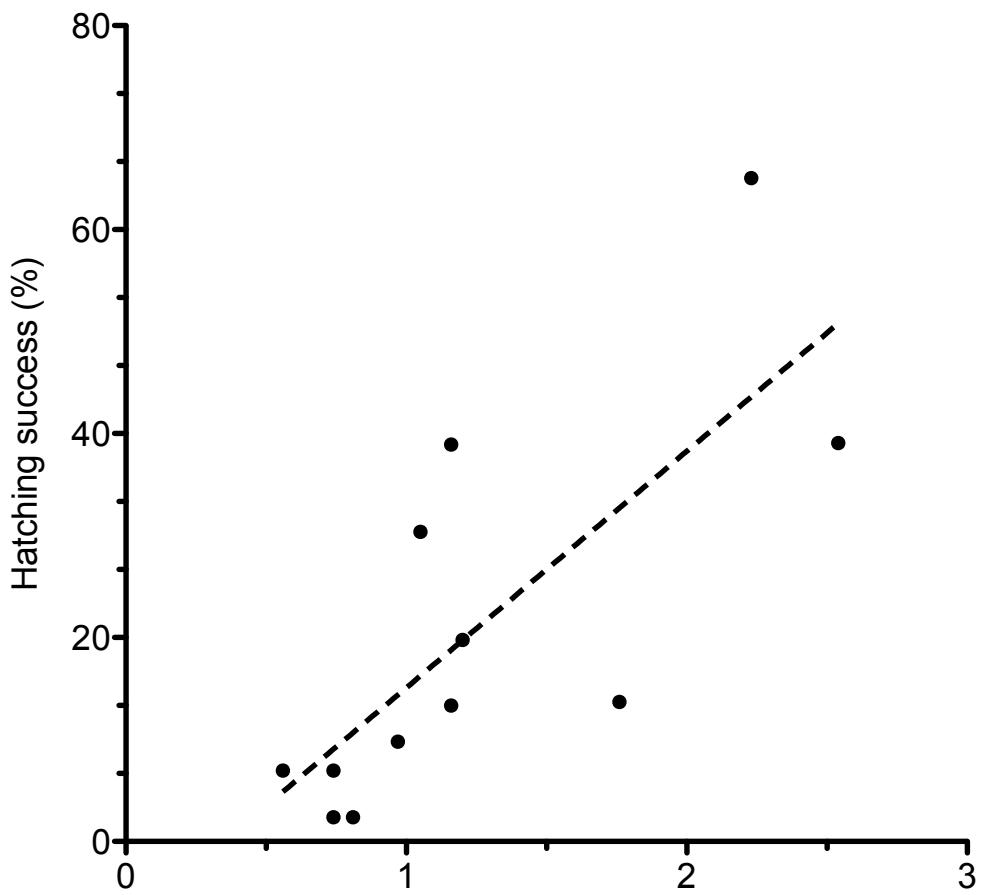

https://mc06.manuscriptcentral.com/cjz-pubs All-trans-ROH (Vitamin $\mathrm{A}_{1} ; \mu \mathrm{g} \cdot \mathrm{mg}^{-1}$ ) dd-ROH (Vitamin $\mathrm{A}_{2} ; \mu \mathrm{g} \cdot \mathrm{mg}^{-1}$ ) 